\title{
Great Minds Do Not Think Alike: Philosophers' Views Predicted By Reflection, Education, Personality, And Other Demographic Differences
}

\author{
Nick Byrd* \\ Stevens Institute of Technology \\ Pearce 308 \\ 1 Castle Point Terrace \\ Hoboken, NJ, 07030 \\ byrdnick.com/contact
}

\begin{abstract}
Acknowledgments
This project was improved by Mark Alfano, Adam Arico, Gunnar Björnsson, Mark Brandt, Hannah Byrd, Stephen Clarke, Michael Clifford, David Colaço, Danial Coren, Josh Correll, Simon Cullen, Pamela Davis-Kean, Chris Dodsworth, Chris Draheim, Brian Earp, Joseph Fraley, Roger Giner-Sorolla, Mike Huemer, Matt Jones, Chick Judd, Jack Justus, Markus Kneer, Joshua Knobe, Thomas J. Leeper, Brian Leiter, Andrew Livingstone, Edouard Machery, Jon Matheson, Josh May, Brad Monton, Gordon Pennycook, Caleb Pickard, Ted Poston, Marshall Thompson, Julia Rohrer, Rob Rupert, John Schwenkler, Nat Stein, Steve Stich, Justin Sytsma, Brian Talbot, Michael Tooley, Oleg Urminsky, Sander van der Linden, Kassidy Velasquez, Edelyn Verona, Justin Weinberg, Jake Westfall, Erin Westgate, Joseph Wilson, Katherine Wolsiefer, and Michael Zahorec.
\end{abstract}

\section{Funding}

This project was funded, in parts, by the University of Colorado at Boulder's Department of Philosophy and Institute of Cognitive Science, by Florida State University's Department of Philosophy and Graduate School, and John Templeton Foundation's grant to the Society for Christian Philosophers. None of these groups had any involvement in the execution of this research or the preparation of this research and they did not receive the paper before publication.

Conflict of Interest - None

Accepted by Review of Philosophy \& Psychology on 2022-03-07. Updates at byrdnick.com/cv. Published DOI: 10.1007/s13164-022-00628-y 


\title{
Great Minds Do Not Think Alike: Philosophers' Views Predicted by Reflection, Education, Personality, And Other Demographic Differences
}

\begin{abstract}
Prior research found correlations between reflection test performance and philosophical tendencies among laypeople. In two large studies (total $\mathrm{N}=1299$ ) —one pre-registered — many of these correlations were replicated in a sample that included both laypeople and philosophers. For example, reflection test performance predicted preferring atheism over theism and instrumental harm over harm avoidance on the trolley problem. However, most reflection-philosophy correlations were undetected when controlling for other factors such as numeracy, preferences for open-minded thinking, personality, philosophical training, age, and gender. Nonetheless, some correlations between reflection and philosophical views survived this multivariate analysis and were only partially confounded with either education or self-reported reasoning preferences. Unreflective thinking still predicted believing in God whereas reflective thinking still predicted believing that (a) proper names like 'Santa' do not necessarily refer to entities that actually exist and (b) science does reveal the fundamental nature of the world. So some robust relationships between reflection and philosophical tendencies were detected even among philosophers, and yet there was clearly more to the link between reflection and philosophy. To this end, demographic and metaphilosophical hypotheses are considered.
\end{abstract}

\section{Keywords}

Cross-cultural psychology, Social Psychology, Personality Psychology, Dual Process Theory, Experimental Philosophy, Judgment and Decision-Making, Cognitive Reflection Test 


\section{Introduction}

Although philosophers admit that they appeal to intuition to motivate some of the premises in their arguments (Chalmers, 2014; Climenhaga, 2018; De Cruz, 2014; Kornblith, 1998; Mallon, 2016; see however Cappelen, 2012; Williamson, 2007; Machery, 2017), reflective thinking has also been considered important for good philosophical inquiry (Korsgaard, 1996; Rawls, 1971) and an essential dimension of philosophically significant topics such as knowledge (Sosa, 1991), logic (Goodman, 1983), ethics (Hursthouse, 1999) and more (Byrd, 2021). So it may be unsurprising that philosophical training correlates positively with reflective reasoning (Livengood et al., 2010). However, both philosophers and scientists have suggested that reflective reasoning tends toward certain philosophical judgments or views (Baron, 1994; Greene, 2013; Sidgwick, 1874). Despite this prediction, it remains unclear how reflection actually relates to philosophers' philosophical tendencies. Although philosophers' beliefs are now being studied empirically (Bourget \& Chalmers, 2014, 2021), we do not yet have many quantitative tests of the links between philosophers' reflection and their philosophical tendencies.

There are, however, quantitative behavioral tests of intuitive and reflective reasoning tendencies. These reflection tests have two key features (Byrd, 2022). First, they lure participants toward a particular incorrect response. Second, they can be solved correctly with a moment's reflection. Consider an example. If a bat and a ball cost $\$ 1.10$ in total and the bat costs $\$ 1.00$ more than the ball, then how much does the ball cost? This well-known bat-and-ball problem is designed to lure people toward incorrectly answering "10 cents" even though a moment's reflection can reveal that the correct answer is actually "5 cents" (Frederick, 2005). When participants read and think aloud about reflection test questions in real time, their verbalizations confirm that correct responses usually involve reconsidering an initial response or offering reasons for another response and that lured responses usually do not (Byrd et al., 2022), much like philosophers' notions of reflection which involves “back[ing] up and bring[ing] an impulse into view" (Korsgaard, 1996 Lecture 3) "to compensate for the immediate force of [that impulse] which might not be the most advantageous" (Taylor, 1976, p. 287).

Some evidence suggests that cognitive reflection tests measure a stable trait (Stagnaro et al., 2018; see however Dames et al., 2021). Regardless of whether reflection test performance fulfills all the characteristics of traits, people who reason more reflectively about math have also reasoned more reflectively about logic (Byrd \& 
GREAT MINDS DO NOT THINK ALIKE

Conway, 2019), Newtonian physics (Gette \& Kryjevskaia, 2019), and probability (e.g., Liberali et al., 2012), suggesting that reflection tests measure reasoning habits that feature in domains beyond the test itself.

Indeed, reflection test performance also predicts variance in certain philosophical tendencies (Byrd, 2021). People who performed worse on reflection tests have also tended toward theism (Pennycook et al., 2016; cf., Gervais et al., 2018), social conservatism (Deppe et al., 2015; Y1lmaz \& Sarıbay, 2016; Yilmaz et al., 2019; cf., Alper \& Yilmaz, 2019; Price-Blackshear et al., 2019), acceptance of utilitarian sacrifices (Patil et al., 2021; Reynolds et al., 2022; cf., Byrd \& Conway, 2019), and moral side effect effects (e.g., Pinillos et al., 2011). However, the robustness of the correlations between reflection test performance and philosophical tendencies is not yet well understood empirically. While some links between reflection and philosophical judgment seem fairly robust (Pennycook et al., 2016; Reynolds et al., 2019, 2022), they are not found in all populations (e.g., Gervais et al., 2018).

One population whose philosophical tendencies and reflection test performance have yet to be thoroughly studied is academic philosophers. Existing research has tended to focus on laypeople and judgments about particular thought experiments rather than philosophers and their general philosophical views — and the latter cannot be straightforwardly inferred from the former. For example, even if reflection test performance predicts the so-called "utilitarian" response to the famous trolley problem among laypeople (Foot, 1967), it would not necessarily follow that reflection test performance predicts believing everything that philosophers consider essential to utilitarianism (Conway et al., 2018). Moreover, because laypeople lack the formal training in philosophy that philosophers receive, the correlates of each population's philosophical tendencies may differ substantially. Laypeople's intuitions about thought experiments have been nudged by subtle differences in wording (Cullen, 2010; Fischer \& Engelhardt, 2020). For example, judgments about free will varied depending on whether thought experiments included 'psychologists', 'mind', and 'thoughts' rather than 'neuroscientist', 'brains', and 'neural processes' (Nahmias et al., 2007). Furthermore, not all intuitions about thought experiments track more considered philosophical judgments because not all thought experiments are, say, paradoxes designed to force people to resolve potential contradictions between two or more common intuitions (see Mandelbaum \& Ripley, 2012; Sinnott-Armstrong, 2007).

So, due to both training and the scope of the judgment, the philosophical view of a professional philosopher may be more considered than the intuition of a layperson who is seeing a philosophical thought experiment for the first time. If that is right, then we may glean additional insight about philosophical thinking by studying not just 
laypeople, but also philosophers — and not just their intuitions about "recherché" cases, but also their acceptance of more general philosophical views (Wilkenfeld, 2020).

So far only a relatively small study of philosophers and their reflection test performance has been published (Yaden \& Anderson, 2021), but this and prior work on the issue used less than optimal reflection tests (Byrd, 2014; Appendix). So there is still a need for a larger conceptual replication and extension of existing findings involving both laypeople and philosophers using both original and state-of-the-art reflection tests as well as measures of both intuitions about particular thought experiments and acceptance of more general philosophical views.

This paper fills this proverbial gap in the literature. Its pre-registered replication and extension finds that some of the links between reflection test performance and philosophical tendencies that have been found among non-philosophers replicated in a sample that includes philosophers even after controlling for factors such as education, mathematical ability, reasoning preferences, personality, age, and gender. Nonetheless, this replication attempt also suggested that most reflection-philosophy correlations were confounded with those other factors. Overall, this suggests that there is certainly more to philosophical tendencies than reflection test performance, but reflection test performance remains a robust predictor of variance in some philosophical tendencies.

\section{From Experiments On Laypeople To Observations Of Laypeople and Philosophers}

Although many philosophical tendencies have correlated with reflection test performance, some correlations between reflection and philosophical tendencies have depended on factors such as culture, education, and personality. Also, experimentally manipulating reflection's impact on philosophical judgments has proven to be more challenging than observing correlations between reflection test performance and philosophical judgments. Reviewing these literatures will help explain the design of the current research.

\subsection{Correlates Of Philosophical Tendencies}

Philosophical tendencies — whether intuitions about thought experiments or broader philosophical stances - have been found to correlate not only with reflection test performance, but also with culture, education, and personality.

Culture. As the scope of psychological research expanded beyond Western, educated, industrialized, rich, and democratic countries (a.k.a., WEIRD countries), researchers realized that many of their findings may not generalize to other countries (e.g., Henrich et al., 2010). Philosophers have also found cross-cultural variation in 
people's philosophical judgments (e.g., Machery et al., 2004; van Dongen et al., 2019). For example, the moral side effect effect that has been found in WEIRD societies seems to have reversed in two traditional, non-WEIRD cultures (Robbins et al., 2017). Cross-cultural differences in responses to moral dilemmas have also been found (Winskel \& Bhatt, 2019). Moreover, the correlations between reflection and philosophical tendencies have varied between WEIRD and non-WEIRD societies (Alper \& Yilmaz, 2019; Gervais et al., 2018). These results raise questions about cross-cultural differences in philosophical thinking (Stich \& Machery, 2022; see however Knobe, 2022) such as whether correlations between reflection and philosophical tendencies will vary by culture—and not just in macrocultural comparisons such as between WEIRD and non-WEIRD nations, but in more micro-cultural comparisons such as between populations that differ along one of the WEIRD dimensions, such as education (Tobia et al., 2013).

Education. Some philosophical judgments have been found to vary by class. For instance, differences in class have correlated with differences in moral judgments about thought experiments (Haidt et al., 1993) and epistemic judgments about thought experiments (Weinberg et al., 2001). However, not all researchers have been able to replicate these findings (Kim \& Yuan, 2015; Seyedsayamdost, 2015; see however de Bruin, 2021). These mixed findings can raise questions about latent variables that could be confounded with philosophical tendencies or class such as education, a common proxy of class (Lee et al., 2003). The idea is that if differences in philosophical tendencies only intermittently correlate with some other variable — whether class or reflection test performance (Baron et al., 2015) - then we could determine if this intermittency has to do with previously unanalyzed differences in a related variable like education . For example, reflection test performance increases with education—particularly training in philosophy (e.g., Livengood et al., 2010)—which can also correlate with certain philosophical tendencies (e.g., Tobia et al., 2013). So if we wanted to know how philosophical tendencies were predicted by variables like class or reflection test performance, both of which correlate with education, then we would want to control for education. After all, it is an empirical question whether a variable like education will explain more variance in philosophical tendencies than our primary predictor variables, whether class or reflection test performance.

Personality. Early experimental philosophy found that intuitions about philosophical thought experiments correlated with personality (Feltz \& Cokely, 2008). In addition to intuitions about thought experiments, personality traits have correlated with religious and political attitudes (Gerber et al., 2011; Saroglou, 2002). More recently, a meta-analysis of 25 studies found robust support for this personality-philosophy relationship among nonphilosophers (Feltz \& Cokely, 2019). There is also some evidence that even philosophers' judgments about thought 
GREAT MINDS DO NOT THINK ALIKE

experiments correlate with personality (Holtzman, 2013). However, some have found that some personalityphilosophy links were not cross-culturally stable (Alper \& Yilmaz, 2019), suggesting that demographic differences may impact whether personality predicts philosophical tendencies.

\subsection{Reflection's Correlates \& Confounders}

Philosophy-reflection correlations have also depended on gender and personality, suggesting that the correlations may be explained by other factors.

Reflection, morality, and gender. Correlations between reflection test performance and moral decisions are sometimes detected among men, but not women (Capraro \& Peltola, 2018). This raises the question of whether reflection-philosophy correlations are explained by some other phenomena such as reflection-gender correlations (e.g., Primi et al., 2018). Such confounding would not be surprising given that some philosophical judgments have been found to be related to both gender (e.g., Friesdorf et al., 2015) and reflection test performance (Byrd \& Conway, 2019).

Reflection, personality, and gender. Reflection has also been found to correlate with openness $(r=-0.08)$, conscientiousness $(r=-0.06)$, extraversion $(r=-0.14)$, agreeableness $(r=-0.08)$, and neuroticism $(r=-0.06)$, but the correlations with agreeableness and conscientiousness were not significant when controlling for gender (Y1lmaz \& Sarıbay, 2016). This raises questions about whether prior relationships between reflection and philosophical judgments could be confounded with factors such as personality or gender (Adleberg et al., 2014; Buckwalter \& Stich, 2010; Easton, 2018).

\subsection{Manipulating vs. Observing Reflection}

Researchers frequently find that inducing reflective and unreflective reasoning is more difficult than earlier work suggested (Deppe et al., 2015; Enke et al., 2021; Meyer et al., 2015; Thompson et al., 2013; Y1lmaz \& Sarıbay, 2016). The difficulty of detecting the effects of momentary manipulations of reflection on philosophical tendencies has reinvigorated normative disputes about experimental philosophy and reflection (Kneer et al., 2022). Of course, it may be that reflection has a different impact on intuitions about strange cases than it does on our settled philosophical stances about more ordinary matters. If so, then even if momentary manipulation of reflection had a reliable impact on intuitions about thought experiments, such manipulations may nonetheless have little or no 
GREAT MINDS DO NOT THINK ALIKE

impact on more considered philosophical views - e.g., the philosophical views of academic philosophers' (Byrd, 2021).

What's more, if the disposition to reflect can have long-term impacts on philosophical tendencies, then differences in reflection test performance may correlate with those philosophical tendencies. Of course, if reflectiveness is unrelated to the psychological processes underlying philosophical tendencies, then it should be difficult to detect correlations between reflection test performance and philosophical tendencies (Knobe, 2021). Also, if philosophers turn out to be so reflective (a lá Livengood et al., 2010) that they reliably get perfect scores on reflection tests, then there will not be enough variance in their reflection test scores to predict variance in philosophers' views. For these reasons, large observational studies and their replications are promising nonexperimental tools for testing potential links between reflection and philosophical tendencies among both philosophers and laypeople.

\subsection{The Current Research}

This paper presents a large conceptual replication of the observed relationships between reflection test performance and philosophical tendencies. This investigation extends this literature by recruiting philosophers, employing less familiar and less mathematical reflection test items, and controlling for nearly a dozen other factors. This pre-registered study was based on a prior study (Appendix; Byrd, 2014) that was motivated in large part by hypotheses generated from the above-mentioned evidence (1-3 below) as well as potentially competing hypotheses posed by anonymous reviewers and fellow philosophers (4-5).

1. Reflective convergence: the bivariate correlations between reflection test performance and certain philosophical tendencies that have been found among laypeople will be found in samples that include philosophers (a lá "reflective persons" in Sidgwick, 1874).

2. Full reflection-philosophy confound: variance in some philosophical tendencies will be explained by demographic factors such as education rather than by reflection test performance (e.g., Baron et al., 2015; Gervais et al., 2018).

3. Partial reflection-philosophy confound: even if reflection test performance correlates with certain philosophical tendencies above and beyond other factors, some of the shared variance between reflection and those philosophical tendencies will be explained by other factors (e.g., Byrd \& Conway, 2019). 
4. Reflective ceiling effect: academic philosophers are so reflective that there will not be enough variance in their reflection test performance to predict variance in their philosophical tendencies (see Livengood et al., 2010).

5. Intuition-belief alignment: Reflection should correlate with both intuitions about particular thought experiments and acceptance of the more general philosophical views associated with those intuitions (e.g., Kahane, 2015). For example, if reflection predicts the "utilitarian" response to the Trolley problem, then reflection would also predict acceptance of the utilitarian view of ethics more generally.

This preregistered replication and extension did not find support for the latter two hypotheses, vindicating the importance of investigating how reflection relates not only to intuitions about particular thought experiments but also to acceptance of more general philosophical views. However, this research did find support for the first three hypotheses, suggesting that even philosophers' reflectiveness can be a robust predictor of their philosophical views related to the existence of god, the reality of scientific theories, and the referents of words even after controlling for factors that better explained variance in other philosophical tendencies. Overall, these data provide further empirical justification of philosophers "preoccupation with reflection" (Doris, 2015 Chapter 2) and its role in philosophical thinking (Byrd, 2021) even if there is more to philosophical tendencies than just reflective reasoning (Kneer et al., 2022; Knobe, 2021; Stich \& Machery, 2022).

Pre-registration, data, and scripts are on the Open Science Framework: osf.io/a98ck. APA and IRB guidelines were followed for all studies and analyses.

\section{Studies}

\subsection{Method}

Participants. Past meta-analyses suggest that the expected philosophy-reflection effect size would be $r \cong$ .18 (Pennycook et al., 2016) or else $r \cong .2$ (Gignac \& Szodorai, 2016). This study was pre-registered and designed to test the replicability of a prior study that included philosophers (Byrd, 2014; Appendix) and improve upon its representativeness by recruiting from more and more varied participant pools. The second study also aimed to obtain at least $80 \%$ power to detect the prior study's average philosophy-reflection bivariate correlation $(r=.1$; Table 4$)$ with an error probability $(\alpha)$ of 0.05 by securing GPower's suggested sample size of 782 participants (Faul et al., 
GREAT MINDS DO NOT THINK ALIKE

2007). LeiterReports.typepad.com, DailyNous.com, and the PHILOSOP listserv recruited 745 respondents while Amazon Mechanical Turk simultaneously recruited 225 respondents. An a priori decision was made to exclude all incomplete surveys $(n=263)$ and insincere surveys $(n=2)$-i.e., two participants admitted that they randomly selected answers-leaving a final sample of 705 (mean age $=36.5 ; 163$ identified as women, 534 as men, and 8 as other; 548 identified as White, 65 as Asian, 43 as Multiethnic, 16 as Black or African American, 2 as American Indian or Native American, and 31 selected "Other").

Procedure and materials. Data were collected in 2019 using Qualtrics in accordance with Florida State University IRB Protocol \#2018.25325 (Byrd, 2020). Participants answered questions about their education, philosophical preferences, and personality before completing a state-of-the-art reflection test.

Education. Participants reported whether they had (or were a candidate for) a Ph.D. in philosophy. Response options were bivalent: yes or no.

Philosophical tendencies. All participants were asked to report their position on the 19 PhilPapers survey items (Chalmers \& Bourget, 2014) that seemed most similar to the kinds of questions that have correlated with reflection test performance among laypeople (e.g., questions related to non-natural entities, non-physical entities, religion, science, politics, and morality) and that were easiest to translate into ordinary language — more on that below. Only 40 participants completed the optional (but pre-registered) 20 -item process dissociation moral dilemma battery (Conway \& Gawronski, 2013), preventing sufficient power to detect expected effects and, therefore, include in the present investigation. Descriptive statistics for the responses to the PhilPapers items can be found in Table 1. 
Table 1. Means and standard deviations for all PhilPapers responses (ranging from -2 to 2).

\begin{tabular}{ll} 
& Mean (SD) \\
\hline 1. Mind: Anti-physicalism (-2) or physicalism (+2)? & $0.07(1.39)$ \\
2. Mental Content: Internalism (-2) or externalism (+2)? & $0.15(1.20)$ \\
3. Language: Russellianism (-2) or Fregeanism (+2)? & $0.58(1.15)$ \\
4. Analytic-Synthetic Distinction: No (-2) or Yes (+2)? & $0.74(1.15)$ \\
5. Time: A-theory (-2) or B-theory (+2)? & $-0.36(1.19)$ \\
6. Laws of nature: Humeanism (-2) or non-Humeanism (+2)? & $0.13(1.25)$ \\
7. Justification: Externalism (-2) or internalism (+2)? & $-0.29(1.12)$ \\
8. Free Will: Incompatibilism (-2) or compatibilism (+2)? & $0.13(1.41)$ \\
9. God: Atheism (-2) or theism (+2)? & $-0.51(1.52)$ \\
10. Meta-ethics: Moral anti-realism (-2) or moral realism (+2)? & $0.34(1.40)$ \\
11. Moral Judgment: Internalism (-2) or externalism (+2)? & $0.17(1.07)$ \\
12. Ethics: Consequentialism (-2) or deontology (+2)? & $-0.04(0.886)$ \\
13. Politics: Libertarianism (-2) or egalitarianism (+2)? & $0.18(1.22)$ \\
14. Science: Anti-realism (-2) or realism (+2)? & $0.42(1.23)$ \\
15. Abstract Objects: Nominalism (-2) or Platonism (+2)? & $-0.37(1.23)$ \\
16. Knowledge: Empiricism (-2) or rationalism (+2)? & $-0.13(1.07)$ \\
17. Metaphilosophy: Naturalism (-2) or non-naturalism (+2)? & $-0.53(1.36)$ \\
18. Trolley Problem: Straight (-2) or turn (+2)? & $0.70(1.24)$ \\
19. Personal Identity: Physical (-) or psychological (+)? & $-0.11(1.32)$ \\
\hline
\end{tabular}

To limit jargon (Knutsen \& Presser, 2010), participants that reported not having or not being a candidate for a $\mathrm{Ph} . \mathrm{D}$. in philosophy received jargon-free translations (Table 2; see also Appendix) developed in cooperation with the Department of Philosophy at the University of Colorado (see also Yaden \& Anderson, 2021).

Following Bourget \& Chalmers (2014) responses to philosophy items were coded from -2 to 2 such that one of the two response options was negative and the other was positive. One advantage of this coding scheme is that it not only reflects the original questions' framing: a choice between two alternatives (as opposed to separate dummy codes for each response option, which fails to reflect participant's contrast class for each response option), but it also reflects the strength of participants endorsement - -i.e. accepting a response option was given a higher absolute value (2) than merely leaning towards a response option (1). Another advantage of this coding scheme manifests when interpreting the results section: negative regression coefficients (bivariate or multivariate) indicate that a variable predicted the philosophical response option that was coded negatively and vice versa. 
GREAT MINDS DO NOT THINK ALIKE

All PhilPapers items from the prior study (Appendix) were re-used in this study, except for a change to one of the jargon-free items about language: The prior study's jargon-free item about language mentioned 'Santa Claus' as an example. Colleagues who commented on drafts of the prior study recommended also including a non-fictitious example to overcome a potential confound between participants' general intuitions about linguistic reference-i.e., to what 'Santa Claus' refers—and more specific intuitions about fictitious (vs. real) referents—e.g., whether 'Santa Claus' refer to something real (Pelc, 1969). So the replication's jargon-free language item mentioned both 'Santa Claus' and 'dolphin' (Appendix).

Table 2. Example of how responses to "Do you have (or are you a candidate for) a Ph.D. in philosophy?" determined PhilPapers survey question that participants received (with descriptive statistics and coding scheme in parentheses)

\begin{tabular}{|c|c|c|c|}
\hline \multicolumn{2}{|c|}{$\begin{array}{c}\text { Yes } \\
\text { (Prior study } N=328 ; \text { Replication } N=280 \text { ) }\end{array}$} & \multicolumn{2}{|c|}{$\begin{array}{c}\text { No } \\
\text { (Prior study } N=267 ; \text { Replication } N=427 \text { ) }\end{array}$} \\
\hline \multicolumn{2}{|c|}{ Free will: incompatibilism or compatibilism? } & \multicolumn{2}{|c|}{$\begin{array}{l}\text { If every event in the universe is determined, do you think it } \\
\text { is possible that there could be free will? }\end{array}$} \\
\hline _ Accept incompatibilism & $(-2)$ & _Accept no & $(-2)$ \\
\hline _ Lean toward incompatibilism & $(-1)$ & _ Lean toward no & $(-1)$ \\
\hline _ I don't know & $(0)$ & _I don't know & $(0)$ \\
\hline _ No inclination & (0) & _ No inclination & (0) \\
\hline __ Lean toward compatibilism & (1) & _ Lean toward yes & (1) \\
\hline _ Accept compatibilism & (2) & _ Accept yes & (2) \\
\hline
\end{tabular}

Personality. Following prior surveys of philosophers (Holtzman, 2013), all participants completed a brief, validated, and widely-used Big-Five personality assessment (Gosling et al., 2003) by rating their agreement with statements such as, "I see myself as disorganized, careless" on a 7-point scale ranging from Disagree strongly to Agree strongly.

Reflection. After completing the education, philosophy, and personality items, participants completed a reflection test battery. Toward the end of the reflection test battery were items adapted from the 3 -item Cognitive Reflection Test (Frederick, 2005) with questions like, “A bat and a ball cost $\$ 1.10$ in total. The bat costs $\$ 1.00$ more than the ball. How much does the ball cost?" 


\section{GREAT MINDS DO NOT THINK ALIKE}

New reflection test. The original cognitive reflection test is so widely used that many participants are already familiar with its questions and answers (e.g., Stieger \& Reips, 2016; Welsh \& Begg, 2017). Indeed, the prior study that motivated this replication found that $28 \%$ of participants reported familiarity with CRT questions and $13 \%$ reported familiarity with CRT answers. Moreover, this reflection test familiarity was often a better predictor of philosophical tendencies than reflection test performance (Appendix Table A3). Fortunately, there is some evidence that performance on this original mathematical reflection test is "robust to multiple exposures" (Stagnaro et al., 2018). Another concern is that CRT performance has been found to be remarkably similar to general math test performance (Attali \& Bar-Hillel, 2020; Erceg et al., 2020; Patel, 2017). To overcome these potential confounds with familiarity and numeracy, the replication's participants completed fourteen newer reflection test items that are less familiar and mostly non-mathematical (e.g., Byrd et al., 2022) before they completed the 3 -item CRT. Three mathematical reflection test prompts asked questions such as, "If it takes 2 nurses 2 min to measure the blood pressure of 2 patients, how long would it take 200 nurses to measure the blood pressure of 200 patients?" (Baron et al., 2015). Nine logical reflection test items such as, "All flowers have petals. Roses have petals. If these two statements are true, can we conclude from them that roses are flowers?" (Markovits \& Nantel, 1989), in which the logical validity of the syllogisms is incongruent with the believability of their conclusions, thereby luring participants into evaluating syllogisms according to believability and not logical validity—a.k.a., belief bias. The replication also included two verbal reflection items from - among others - Sirota and colleagues (2020) including,

“Ann's father has a total of five daughters: Lala, Lele, Lili, Lolo, and What is the name of the fifth daughter?"

All reflection test responses were collected using a validated multiple choice format (Sirota \& Juanchich, 2018). To reduce measurement error (Machery, 2021), both the lured and correct response were used to create unreflective and reflective parameters and all other non-lured incorrect responses were ignored (Byrd, 2022): An unreflective parameter was computed by summing only lured responses and a reflective parameter was computed by summing only correct responses.

To test for reflection while controlling for variables that are thought to be confounded with reflection (Campitelli \& Labollita, 2010; Liberali et al., 2012; Primi et al., 2016; Szaszi et al., 2017), the replication also included more general measures of logical competence, numeracy, and preferences for open-minded thinking.

Logical competence. Of the seven logical syllogisms, three included quantifiers (e.g., 'some' or 'all') as follows: "In a box, some red things are square, and some square things are large. What can we conclude? (a) Some 
red things are large. (b) All red things are large. (c) We can't conclude anything about red things and large things" (Johnson-Laird \& Bara, 1984). The other four syllogisms lacked quantifiers but contained unfamiliar pseudowords such as "All laloobays are rich. Sandy is a laloobay. If these two statements are true, can we conclude from them that Sandy is rich?" (Baron et al., 2015). Correct responses to these questions were summed for each participant.

Numeracy. To measure mathematical competence, participants were asked to complete the 4-item Berlin Numeracy Test with questions such as, "Imagine we are throwing a five-sided die 50 times. On average, out of these 50 throws how many times would this five-sided die show an odd number (1, 3 or 5)? (a) 5 out of 50 throws, (b) 25 out of 50 throws, (c) 30 out of 50 throws, or (d) None of the above" (Cokely et al., 2012). Correct responses were summed for each participant.

Open-minded thinking. Next participants completed the 10-item Actively Open-Minded Thinking scale (Baron, 2018) by rating their agreement with statements such as "People should revise their beliefs in response to new information or evidence" on a 5-point scale ranging from Completely disagree to Completely agree. After reverse-coding items accordingly, Actively Open-Minded Thinking (AOT) ratings were summed.

Age. Some evidence suggests that age correlates with reflection (Hertzog et al., 2018) and personality (Harris et al., 2016). So participants in the replication reported their age by selecting their year of birth. Age was computed by subtracting these birth years from the year that the study was conducted.

\subsection{Results}

Descriptive statistics. Table 3 reports sample sizes, ranges, means and standard deviations for reflection test performance among philosophers and non-philosophers from the present studies as well as others. In line with past work (e.g., Livengood et al., 2010), philosophers were more reflective than other samples. Having graduate coursework in philosophy predicted more correct responses $(0.14<r<0.38, p<0.001)$ and fewer lured responses ($0.12<r<-0.38, p<0.004)$ on reflection tests from both studies. Even among those with this advances training in philosophy in the replication, the number of years spent studying philosophy predicted more correct responses $(\beta=$ $0.26, p=0.003)$ and fewer lured responses $(\beta=-0.24, p=0.007)$ on the improved reflection test controlling for the number of philosophy courses taught, which was not related to reflection test performance. 
Table 3. Descriptive statistics about reflection test performance in this paper as well as other studies.

\begin{tabular}{rcccc} 
Lured Responses On The Original 3-item CRT & $\boldsymbol{N}$ & Range & Mean & Std. Deviation \\
\cline { 2 - 5 } Philosophers (prior study) & 594 & $0-3$ & 0.42 & 0.72 \\
\cline { 2 - 5 } Philosophers and mTurk Workers (replication) & 705 & $0-3$ & 0.58 & 0.87 \\
\cline { 2 - 5 } Yale students (Meyer et al., 2015) & 786 & $0-3$ & 0.62 & 0.88 \\
\cline { 2 - 5 } mTurk Workers (ibid.) & 5191 & $0-3$ & 1.27 & 1.25 \\
\cline { 2 - 5 } New Haven residents (ibid.) & 263 & $0-3$ & 1.38 & 1.2 \\
\cline { 2 - 4 } & & &
\end{tabular}

\begin{tabular}{rcccc} 
Correct Responses On The Original 3-item CRT & $\boldsymbol{N}$ & Range & Mean & Std. Deviation \\
\cline { 2 - 5 } Philosophers (prior study) & 594 & $0-3$ & 2.34 & 0.90 \\
\cline { 2 - 5 } Philosophers and mTurk Workers (prior study) & 705 & $0-3$ & 2.26 & 1.00 \\
\cline { 2 - 5 } Yale students (Meyer et al., 2015) & 786 & $0-3$ & 1.98 & 1.08 \\
\cline { 2 - 5 } mTurk Workers (ibid.) & 5191 & $0-3$ & 1.39 & 1.22 \\
\cline { 2 - 5 } New Haven residents (ibid.) & 263 & $0-3$ & 1.01 & 1.25 \\
\cline { 2 - 4 } & &
\end{tabular}

\begin{tabular}{cccccc} 
New 14-item Reflection Test - Math, Logic, \& Verbal & $\boldsymbol{N}$ & Range & Mean & Std. Deviation \\
\cline { 2 - 5 } Philosophers' and mTurk Workers' lured responses (replication) & 705 & $0-14$ & 3.85 & 2.95 \\
\cline { 2 - 5 } Philosophers' and mTurk Workers' correct responses (replication) & 705 & $0-14$ & 9.82 & 3.2 \\
\cline { 2 - 5 }
\end{tabular}

Bivariate regression analysis. All bivariate correlations between philosophical responses and reflection test performance from both studies are reported in Table 4. Aligning with the reflective convergence hypothesis, philosophers' reflection test performance predicted philosophical views about language (Russellianism or Fregeanism) and God (atheism rather than theism) as well as intuitions about the Trolley problem (instrumental harm rather than harm rejection) for all reflection tests in both studies - most of which have been found among laypeople (Byrd \& Conway, 2019; I. Hannikainen \& Cova, In prep.; Pennycook et al., 2016; see however Reynolds et al., 2022). Correlations between reflection test performance and philosophical preferences about internalism (vs. externalism) about moral judgment, consequentialist (vs. deontological) ethics, and empiricism (vs. rationalism) about knowledge were not detected in either the prior study or the replication. Insofar as those correlations are widely found among laypeople, this would pose a challenge to the reflective convergence hypothesis. Notably, the correlation between reflection and philosophical tendencies about language (Russellianism rather than Fregeanism) from the prior study reversed in the replication (Fregeanism rather than Russellianism). This change could suggest 
that the prior study's result about language was a false positive. It may also be an unexpected result of the aforementioned wording change from "“Santa Claus"” to "“Santa Claus' or 'dolphin"”. Further investigation could help arbitrate between these null and pragmatic cue hypotheses (Cullen, 2010). 


\section{GREAT MINDS DO NOT THINK ALIKE}

Table 4. Correlations between philosophical tendencies and both lured and correct responses to the original 3-item (prior study and replication) as well as a larger, less familiar, less mathematical reflection test battery (replication).

\begin{tabular}{|c|c|c|c|c|c|c|}
\hline \multirow{2}{*}{$\begin{array}{l}\text { PhilPapers Items and coding scheme } \\
\text { (a la Bourget \& Chalmers, 2014) }\end{array}$} & \multicolumn{2}{|c|}{ Prior study $(2014, N=594)$} & \multicolumn{4}{|c|}{ Replication (2019, $N=705)$} \\
\hline & $\begin{array}{c}\text { Lured } \\
\text { (3-item CRT) }\end{array}$ & $\begin{array}{c}\text { Correct } \\
\text { (3-item CRT) }\end{array}$ & $\begin{array}{c}\text { Lured } \\
\text { (3-item CRT) }\end{array}$ & $\begin{array}{c}\text { Correct } \\
\text { (3-item CRT) }\end{array}$ & $\begin{array}{c}\text { Lured } \\
\text { (New CRT) }\end{array}$ & $\begin{array}{c}\text { Correct } \\
\text { (New CRT) }\end{array}$ \\
\hline 1. Mind: Anti-physicalism (-) or physicalism (+)? & -.06 & .06 & $-.14^{\star * *}$ & $.17^{\star * *}$ & $-.29^{* * *}$ & $.29 * * *$ \\
\hline 2. Mental Content: Internalism (-) or externalism (+)? & -.05 & .02 & $-.13^{\star * *}$ & $.15^{\star \star *}$ & $-.22^{\star * *}$ & $.22^{* * *}$ \\
\hline 3. Language: Russellianism (-) or Fregeanism (+)? & $.10^{*}$ & -.05 & $-.09^{*}$ & $.12^{\star *}$ & $-.13^{\star * *}$ & $.17^{* * *}$ \\
\hline 4. Analytic-Synthetic Distinction: No (-) or Yes (+)? & .07 & -.04 & .01 & -.03 & $.09^{*}$ & $-.08^{*}$ \\
\hline 5. Time: A-theory $(-)$ or B-theory $(+)$ ? & -.01 & .04 & $-.11^{* *}$ & .07 & $-.11^{* *}$ & $.11^{* *}$ \\
\hline 6. Laws of nature: Humeanism (-) or non-Humeanism (+)? & -.02 & .03 & -.00 & .03 & -.07 & $.08^{*}$ \\
\hline 7. Justification: Externalism (-) or internalism (+)? & .03 & -.05 & -.06 & .06 & $-.09^{*}$ & $.09^{*}$ \\
\hline 8. Free Will: Incompatibilism (-) or compatibilism (+)? & $-.09^{*}$ & $.08^{*}$ & -.04 & .03 & $-.11^{* *}$ & $.11^{* *}$ \\
\hline 9. God: Atheism (-) or theism (+)? & $.09^{*}$ & $-.08^{*}$ & $.24^{* * *}$ & $-.26^{\star \star *}$ & $.35^{\star * *}$ & $-.35^{\star * *}$ \\
\hline 10. Meta-ethics: Moral anti-realism (-) or moral realism (+)? & .06 & -.04 & -.05 & .06 & $-.08^{*}$ & $.08^{*}$ \\
\hline 11. Moral Judgment: Internalism (-) or externalism (+)? & -.00 & .04 & -.03 & .02 & .01 & -.02 \\
\hline 12. Ethics: Consequentialism (-) or deontology $(+)$ ? & .00 & -.06 & .01 & -.03 & -.01 & .00 \\
\hline 13. Politics: Libertarianism (-) or egalitarianism (+)? & -.03 & .03 & $-.12^{\star * *}$ & $.15^{\star * *}$ & $-.23^{\star * *}$ & $.24^{\star * *}$ \\
\hline 14. Science: Anti-realism (-) or realism (+)? & -.05 & .04 & $-.19^{* * *}$ & $.21^{* * *}$ & $-.21^{* * *}$ & $.23^{\star * *}$ \\
\hline 15. Abstract Objects: Nominalism (-) or Platonism (+)? & -.01 & .03 & -.07 & $.08^{*}$ & $-.09^{*}$ & $.09 * *$ \\
\hline 16. Knowledge: Empiricism (-) or rationalism (+)? & -.05 & .02 & -.03 & .03 & -.03 & .03 \\
\hline 17. Metaphilosophy: Naturalism (-) or non-naturalism $(+)$ ? & .03 & -.03 & $.09^{*}$ & $-.11^{* *}$ & $.11^{* *}$ & $-.10^{* *}$ \\
\hline 18. Trolley Problem: Straight (-) or turn (+)? & $-.13^{* *}$ & $.14^{* * *}$ & $-.12^{\star \star *}$ & $.15^{\star \star *}$ & $-.18^{* * *}$ & $.19^{* * *}$ \\
\hline 19. Personal Identity: Physical (-) or psychological (+)? & $-.10^{*}$ & .07 & -.07 & .07 & $-.16^{\star * *}$ & $.17^{* * *}$ \\
\hline
\end{tabular}

Note: ${ }^{*} p<.05,{ }^{* *} p<.01,{ }^{* * *} p<.001$. 
GREAT MINDS DO NOT THINK ALIKE

The correlations detected in both studies ranged from small to large (Gignac \& Szodorai, 2016). Visualizations of all bivariate reflection-philosophy correlations for both studies can be found in the Appendix (Figures A1 through A4). As a result of a larger sample and better measures, the replication was able to directly and conceptually replicate multiple results from the prior study, often detecting larger correlations than anticipated in the a priori power analysis. The most and largest correlations between reflection test performance and philosophical tendencies were detected with the new, less mathematical, less familiar 14-item reflection test in the replication. Nonetheless, even the small correlations between this test and philosophical tendencies aligned with past work on non-philosophers. For instance, the replication detected correlations between reflection test performance and nonnaturalism (e.g., Pennycook et al., 2012).

Nonetheless, the replication conducted twice as many bivariate correlation tests because it reported correlations with both the original 3-item CRT and the updated reflection test battery. To err on the side of conservatism (Benjamin et al., 2018; Curtin \& Schulz, 1998) this replication included in the multiple regression analyses only the philosophy items whose bivariate correlations with reflection test performance (Table 4) had $p$ values less than or equal to the Bonferroni-corrected $\alpha$ threshold of 0.001 (i.e., 0.05 divided by 76 - the number of bivariate correlations reported in the replication-rounded to 3 decimal places).

As pre-registered, only when reflection test performance predicted philosophical tendencies above and beyond other factors in the subsequent multiple regression analyses was partial confounding of these philosophyreflection correlations tested.

Multiple regression analysis. The bivariate correlational analyses did not account for other variables that sometimes correlate with unreflective and reflective reasoning such as prior familiarity with the CRT (e.g., Stieger \& Reips, 2016), philosophical training (Livengood et al., 2010), gender (e.g., Primi et al., 2018), personality (Yılmaz \& Sarıbay, 2016), or other demographics (e.g., Yilmaz \& Alper, 2019). So it is not clear whether philosophical judgments correlate with reflection per se or with other variables that correlate with reflection. To test the relationship between reflection and philosophical judgments while controlling for these variables, pre-registered multiple regression analyses were conducted (Table 5). Overall, the multiple regression analysis found that the improved reflection test predicted variance in more philosophical tendencies in the replication (Table 5) than the original 3-item mathematical reflection test predicted in the prior study (Appendix Table A2) after controlling for other factors such as education and gender. More specific findings from the multiple regression are as follows. 
Table 5. Standardized multiple regression coefficients predicting philosophical tendencies ( -2 to 2 a la Bourget \& Chalmers, 2014) from all measures in the replication $(N=705)$. Each column is a separate multiple regression analysis.

\begin{tabular}{|c|c|c|c|c|c|c|c|c|}
\hline & $\begin{array}{l}\text { Mind } \\
\text { Anti-physicalism } \\
\text { or physicalism? }\end{array}$ & $\begin{array}{l}\text { Mental Content } \\
\text { Internalism or } \\
\text { externalism? }\end{array}$ & $\begin{array}{c}\text { Language } \\
\text { Russellianism or } \\
\text { Fregeanism? }\end{array}$ & $\begin{array}{l}\text { God } \\
\text { Atheism or } \\
\text { theism? }\end{array}$ & $\begin{array}{c}\text { Politics } \\
\text { Libertarianism or } \\
\text { egalitarianism? }\end{array}$ & $\begin{array}{c}\text { Science } \\
\text { Anti-realism } \\
\text { or realism? }\end{array}$ & $\begin{array}{c}\text { Trolley } \\
\text { Problem: } \\
\text { Straight or turn? }\end{array}$ & $\begin{array}{c}\text { Personal Identity } \\
\text { Physical or } \\
\text { psychological? }\end{array}$ \\
\hline Lured New CRT & -.11 & -.08 & $.41^{*}$ & $.43^{*}$ & -.16 & .28 & .02 & .01 \\
\hline Correct New CRT & .09 & -.04 & $.54^{\star *}$ & .25 & .13 & $.44^{*}$ & -.01 & .00 \\
\hline Philosophy Ph.D. & .01 & .06 & $-.53^{\star * *}$ & -.02 & $.27^{\star \star *}$ & .05 & $.08^{\dagger}$ & $.28^{\star * *}$ \\
\hline Gender $(M-W)$ & -.02 & -.02 & -.00 & $.07^{\dagger}$ & -.02 & -.01 & .02 & .03 \\
\hline Extraversion & .00 & -.04 & -.03 & $.06^{\dagger}$ & -.04 & -.05 & $.08^{*}$ & -.04 \\
\hline Agreeableness & -.04 & $-.11^{\star *}$ & .03 & $.08^{*}$ & $.13^{\star * *}$ & .01 & $-.10^{\star *}$ & -.04 \\
\hline Conscientiousness & -.05 & -.02 & -.01 & -.01 & .05 & -.02 & -.03 & -.00 \\
\hline Stability & -.02 & -.03 & .05 & $.09^{*}$ & -.04 & .04 & -.01 & $.07^{\dagger}$ \\
\hline Openness & -.02 & $.08^{*}$ & .01 & -.02 & -.02 & -.01 & .01 & .02 \\
\hline Logical Competence & -.05 & $.10^{\dagger}$ & $.17^{\star * *}$ & .02 & $.16^{\star * *}$ & -.06 & .06 & $.15^{\star *}$ \\
\hline Numeracy (BNT) & .05 & $.08^{\dagger}$ & -.01 & -.05 & -.05 & .07 & $.08^{\dagger}$ & $-.07^{\dagger}$ \\
\hline Open-minded Thinking & $.15^{\star *}$ & -.01 & $.21^{\star * *}$ & $-.22^{\star * *}$ & .07 & $.10^{*}$ & $.16^{\star \star *}$ & -.02 \\
\hline Age & .03 & .05 & $.06^{\dagger}$ & -.02 & -.06 & .05 & .00 & -.02 \\
\hline Combined Adjusted $R^{2}$ & $.09^{* * *}$ & $.08^{\star * *}$ & $.33^{* * *}$ & $.17^{* \star *}$ & $.15^{\star \star \star}$ & $.06^{\star * *}$ & $.07^{* \star *}$ & $.10^{\star \star *}$ \\
\hline
\end{tabular}

Note: $\dagger p<.1,{ }^{*} p<.05,{ }^{* *} p<.01,{ }^{* * *} p<.001$

Reflection test performance. Further aligning with the reflective convergence hypothesis, reflection test performance in the replication study correlated with philosophical tendencies about language (Russellianism vs. Fregeanism), God (atheism vs. theism), and science (anti-realism vs. realism) above and beyond other factors (Table 5). On average, the more that people selected the faulty lured response on reflection tests, the more that they tended to accept theism (rather than agnosticism or atheism) - further aligning with existing meta-analyses of laypeople (e.g., Pennycook et al., 2016). Also, selecting the correct response on reflection tests correlated with thinking that science describes the fundamental nature of the world rather than merely producing useful predictions and technology, extending similar results among laypeople (Byrd \& Białek, 2021). Unexpectedly, both lured and correct reflection test responses correlated with thinking that the use of words like 'Santa Claus' or 'dolphin' entail merely that the ideas of Santa Claus and dolphins exist (not that these referents actually exist)—an unexpected result that receives more attention in the partial confound analyses.

Other variables. Reflection test performance no longer explained much variance in some philosophical tendencies after controlling for other variables, suggesting that some bivariate reflection-philosophy correlations were confounded with these other variables. In both studies those other variables included education (i.e., having or 
being a candidate for a Ph.D. in philosophy) and personality—aligning with past work on non-philosophers (e.g., Feltz \& Cokely, 2019; Hannikainen et al., 2019) and with the full reflection-philosophy confound hypothesis.

In the prior study, familiarity with reflection test answers, gender, and citizenship in a WEIRD country were more predictive of some philosophical tendencies than reflection test performance (Appendix Table A2). Once again, this aligns with demographic differences among non-philosophers (e.g., Alper \& Yilmaz, 2019; Friesdorf et al., 2015; Strimaitis, 2018; van Dongen et al., 2019; Welsh \& Begg, 2017). The replication found that logical competence and self-reported preferences for open-minded thinking also predicted more variance in some philosophical tendencies than reflection test performance, which is compatible with prior research on laypeople (e.g., Baron et al., 2015). Notably, neither age nor numeracy predicted much variance in philosophical tendencies beyond the other factors.

Overall, this multiple regression analysis suggests that the reflection-philosophy correlations were not always explained by correlates of reflection such as numeracy, logical competence, preferences for open-minded thinking, personality, or gender. Moreover, this reaffirms the value of controlling for different reasoning tests and preferences when predicting philosophical tendencies (Byrd \& Conway, 2019).

Partial confound analysis. Both the prior and the replication studies found that reflection test performance predicted some philosophical tendencies above and beyond potentially confounding factors. In short, full confounding of some reflection-philosophy relationships was not detected. This satisfied the pre-registered conditions for mediation analysis (a lá Baron \& Kenny, 1986) to quantify the partial confounding in these reflection-philosophy relationships - something that cannot be inferred from the aforementioned multiple regression analyses alone. While mediation analysis is often thought to be limited to experimental designs, "from a strictly statistical perspective [mediation] is indistinguishable from confounding" (Rohrer et al., 2021), which is the phenomena of interest in this paper. So the mediation analyses will be referred to as confounding analyses. Monte Carlo power analysis for indirect effects running 1000 replications and 20000 draws per repetition suggested that the replication had $97 \%$ power to detect confounding relationships (Schoemann et al., 2017).

The two variables that predicted as much or more variance in philosophers' views as reflection test performance predicted in the multivariate analyses were education (i.e., whether one had completed graduate level coursework in philosophy) and self-reported preferences about open-minded thinking. So the following analyses first tested how philosophy Ph.D. status was partially confounded with the relationship between reflection and 
philosophical tendencies about language (Russellianism vs. Fregeanism), God (atheism vs. theism), and science (anti-realism vs. realism). If no confounding with philosophy Ph.D. status was detected, then confounding with actively open-minded thinking preferences was tested. To avoid the limitations of the prior study such as CRT familiarity, reflection test performance is based on the new (rather than the original) reflection test items from the replication.
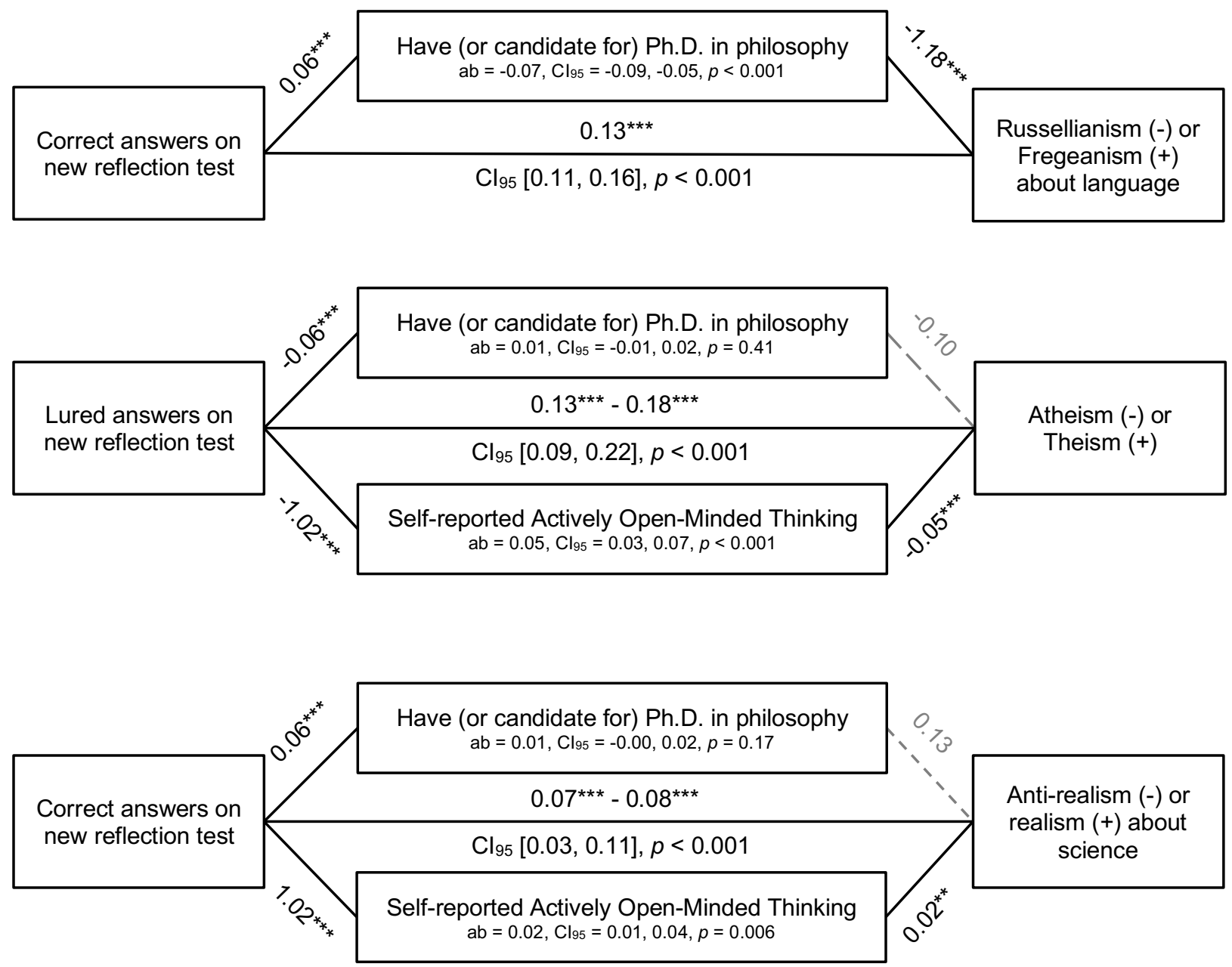

Figure 1. Analysis of partial confounding between reflection test performance and philosophical tendencies about language, God, and science by education and/or preferences for actively open-minded thinking from the replication $(N=705)$.

Quantification of the confounding relationships are in Figure 1. Either graduate level training in philosophy or self-reported preferences for open-minded thinking — but not both—accounted for some of the variance in 
philosophical views that was otherwise be accounted for by reflection test performance. For two of the three reflection-philosophy relationships, confounding with philosophical training was not detected.

\section{General Discussion}

In two large studies of mostly philosophers (total $N=1299$ ), correlations between reflection test performance and philosophical tendencies were detected, supporting the first reflective convergence hypothesis and challenging the fourth reflective ceiling effect hypothesis. Most of these correlations between reflection test performance and philosophical tendencies were not detected when controlling for confounding factors, in line with the second full reflection-philosophy confound hypothesis. However, the philosophy-reflection correlations that survived this multivariate analysis were nonetheless partially confounded with either completion of graduate-level coursework in philosophy or self-reported preferences about actively open-minded thinking, supporting the third partial reflection-philosophy confound hypothesis. Also, although correct reflection test answers correlated with the utilitarian or harm-minimizing response to the trolley problem, those correct reflection test responses did notcontrary to the fifth intuition-belief alignment hypothesis - also correlate with endorsement of the utilitarian ethical view that has been said to motivate such intuitions. Overall, these data suggest that most of the reflection-philosophy correlations studied herein could be confounded with other reasoning tendencies or demographic factors.

Nonetheless, correlations between reflection test performance and judgments about the existence of entities like God and about the truth of scientific theories that have been found among laypeople were detected in samples that included philosophers - even after controlling for graduate-level coursework in philosophy and nearly a dozen other demographic variables.

\subsection{Reflection \& Metaphilosophical Orientation}

Philosophers' and laypeople's reflection test performance reliably predicted beliefs about what exists, controlling for confounds. Believing in God was more common, on average, the more that people fell for the lure on reflection tests. However, believing that words like 'Santa Claus' referred to things that actually exist or that scientific theories don't describe the fundamental nature of the world was less common, on average, the more that people correctly answered reflection tests.

Prior research on philosophers found that preferences for theism clustered together with "anti-naturalist" philosophical tendencies such as non-naturalism (Bourget \& Chalmers, 2014). In the same data, anti-realism about 
science clustered together with other "anti-realist" tendencies like the aforementioned Fregean view to proper names (e.g., 'Santa Claus'). So in the present data, seemingly non-naturalist and anti-realist philosophical tendencies were more common among philosophers and laypeople who were more likely to rely on faulty intuitions on reflection tests. Independent support for such a reflection-metaphilosophy hypothesis is conferred by studies finding that less reflective reasoners were more prone to having paranormal beliefs (Aarnio \& Lindeman, 2005; Erceg et al., 2019; Gianotti et al., 2001; Pennycook et al., 2012), interpreting metaphors literally (Mækelæ et al., 2018), and believing in God (Pennycook et al., 2013, 2014, 2016; Zuckerman et al., 2019; cf., Yilmaz \& Isler, 2019).

Consider another reason to countenance the reflection-metaphilosophy hypothesis. Scientific training involves not only identifying one's initial intuition or prediction, but also remaining skeptical about that initial reaction while one tests it. So scientific experience might translate well to reflection tests which require participants to remain skeptical of their initial impulse until they can double check that it satisfies all of the question's criteria (Byrd, 2022). Also, the scientific education that trains one to reflect on one's initial impulse tends to be realist and methodologically naturalist. As a result, scientific thinking may correlate with both more reflective, more naturalist and more scientifically realist thinking, which could result in the bivariate correlation between reflection and naturalist thinking that was observed in the replication — even if this did not breach the Bonferroni-corrected significance threshold $(p<0.001)$. Experimental and longitudinal studies of the effect of scientific training could better test this part of the reflection-metaphilosophy hypothesis.

\subsection{Reflection \& Demographic Defaults}

The metaphilosophical hypothesis is just that: a hypothesis. Although compatible with some of the present evidence, it is not the only explanation of the present evidence. Ultimately, the promise of this metaphilosophical hypotheses depends on the results of further research. So even if the metaphilosophical hypothesis is consistent with the data presented in this paper, additional hypotheses might fruitfully supplement it. One such supplemental hypothesis is a demographic difference hypothesis (Henrich et al., 2010; Kitayama et al., 2019; Stich \& Machery, 2022).

Multiple regression in the prior study (Appendix Table A2) revealed that reflection test performance no longer predicted philosophical judgments about whether determinism precluded free will when controlling for whether philosophers were citizens of a WEIRD country. Other studies also find evidence that reflection-philosophy correlations can be confounded with demographic factors. For example, the relationship between reflection and 
atheism has varied across countries (Gervais et al., 2018). These demographic variations in the relationship between reflection and philosophical tendencies may generate fruitful hypotheses. For example, perhaps reflection leads one to question not only one's initial impulse on a reflection test (Martiny-Huenger et al., 2020), but also the dominant philosophical tendencies of one's household, community, or society. Indeed, this is one potential explanation of why reflection may correlate with disbelief in God in the long-run even though momentary instances of reflection can cause atheists to question their disbelief (Yilmaz \& Isler, 2019). Of course, if theism is sufficiently intuitive, then analytic atheist correlations may not fully reverse when the demographic default is atheism. Perhaps this is why reflection test performance correlated weakly with atheism (rather than in the opposite, theism direction) in societies with lower levels of religiosity (Weiss et al., 2021). This sort of default-interventionist approach (Evans, 2019) to demographic variation in reflection-philosophy correlations might be able to explain puzzles about reflectionphilosophy correlations that the other hypotheses cannot explain on their own.

Of course, it may be that both metaphilosophical and demographic factors are related to philosophical tendencies (Baron, 2020). There is growing support for such a dual-inheritance hypothesis about philosophical tendencies among non-philosophers (Baron et al., 2022; Gervais et al., in prep.; White et al., 2021). So subsequent research might profitably extend this literature by testing dual inheritance hypotheses about philosophical tendencies among both laypeople and people with advanced education from different parts of the world.

\section{Conclusion}

The current research replicated and clarified some the relationships between reflection and philosophical tendencies. The reflective convergence hypothesis was largely supported: philosophers' reflection test performance correlated with some of the philosophical tendencies that have correlated with non-philosophers' reflection test performance — for instance, judgments about God, science, and politics, and moral dilemmas—as well as other philosophical tendencies — for example, views about language, mind, mental content, time, and personal identity.

However, after controlling for other factors such as numeracy, preferences for open-minded thinking, personality, philosophical training, age, and gender, most of these correlations between reflection and philosophical tendencies were undetected, supporting the reflection confound hypothesis.

The partial reflection-philosophy confound hypothesis was also supported. When reflection did correlate with philosophical tendencies over and above other factors, part of these reflection-philosophy relationships were confounded with either philosophical training or self-reported reasoning preferences. 
GREAT MINDS DO NOT THINK ALIKE

Contrary to the intuition-belief alignment hypothesis, while reflection correlated with intuitions about the trolley problem, it did not correlate much with acceptance of the consequentialist ethical view that has been thought to motivate such intuitions (e.g., Foot, 1995). So one should not necessarily infer that utilitarianism as a view somehow involves more reflection just because correct reflection test answers predict a so-called utilitarian response to a moral dilemma. This is not to say that the two types of philosophical judgments are unrelated-e.g., that accepting utilitarian tradeoffs in sacrificial moral dilemmas allegedly fails to correspond with endorsement of consequentialist ethics (Kahane, 2015; Kahane et al., 2015). On the contrary, the so-called utilitarian response to the trolley problem correlated with a preference for consequentialist ethics in both the prior study $(r=-0.25, p<0.001)$ and in the replication $(r=-0.1, p=0.008)$-a finding that aligns with earlier samples that also included philosophers (Conway et al., 2018). So while intuitions about odd cases may in fact relate to acceptance of more general philosophical views that are relevant to the case, the current evidence suggests that reflection test performance may be related to the former but not the latter.

Finally, contrary to the ceiling effect hypothesis, there were some robust relationships between philosophers' reflection test performance and their philosophical tendencies. Above and beyond other factors, unreflective thinking still predicted believing in God. Likewise, reflective thinking still predicted believing that proper names like 'Santa Claus' do not necessarily refer to entities that actually exist and believing that science does reveal the fundamental nature of the world. In other words, some differences in laypeople's and philosophers' philosophical tendencies corresponded, in part, to not thinking alike during reflection tests.

\section{References}

Aarnio, K., \& Lindeman, M. (2005). Paranormal beliefs, education, and thinking styles. Personality and Individual Differences, 39(7), 1227-1236.

Adleberg, T., Thompson, M., \& Nahmias, E. (2014). Do Men and Women Have Different Philosophical Intuitions? Further Data. Philosophical Psychology, 1-27.

Alper, S., \& Yilmaz, O. (2019). How is the Big Five related to moral and political convictions: The moderating role of the WEIRDness of the culture. Personality and Individual Differences, 145, 32-38. https://doi.org/10.1016/j.paid.2019.03.018

Attali, Y., \& Bar-Hillel, M. (2020). The false allure of fast lures. Judgment and Decision Making, 15(1), 93-111. http://journal.sjdm.org/19/191217/jdm191217.html

Baron, J. (1994). Nonconsequentialist decisions. Behavioral and Brain Sciences, 17(1), 1-10. https://doi.org/10.1017/S0140525X0003301X

Baron, J. (2018). Actively Open-minded Thinking Scale. The Society for Judgment and Decision Making. http://www.sjdm.org/dmidi/Actively_Open-Minded_Thinking_Beliefs.html 
Baron, J. (2020). Religion, cognitive style, and rational thinking. Current Opinion in Behavioral Sciences, 34, 64 68. https://doi.org/10.1016/j.cobeha.2019.12.015

Baron, J., Isler, O., \& Yilmaz, O. (2022). Actively open-minded thinking and the political effects of its absence. PsyArXiv. https://doi.org/10.31234/osf.io/g5jhp

Baron, J., Scott, S., Fincher, K., \& Metz, S. E. (2015). Why does the Cognitive Reflection Test (sometimes) predict utilitarian moral judgment (and other things)? Journal of Applied Research in Memory and Cognition, 4(3), 265-284. https://doi.org/10.1016/j.jarmac.2014.09.003

Baron, R. M., \& Kenny, D. A. (1986). The moderator-mediator variable distinction in social psychological research: Conceptual, strategic, and statistical considerations. Journal of Personality and Social Psychology, 51(6), 1173-1182. https://doi.org/10.1037//0022-3514.51.6.1173

Benjamin, D. J., Berger, J. O., Johannesson, M., Nosek, B. A., Wagenmakers, E.-J., Berk, R., Bollen, K. A., Brembs, B., Brown, L., Camerer, C., Cesarini, D., Chambers, C. D., Clyde, M., Cook, T. D., Boeck, P. D., Dienes, Z., Dreber, A., Easwaran, K., Efferson, C., ... Johnson, V. E. (2018). Redefine statistical significance. Nature Human Behaviour, 2(1), 6. https://doi.org/10.1038/s41562-017-0189-z

Bourget, D., \& Chalmers, D. (2014). What do philosophers believe? Philosophical Studies, 170(3), 465-500. https://doi.org/10.1007/s11098-013-0259-7

Bourget, D., \& Chalmers, D. (2021). Philosophers on Philosophy: The 2020 PhilPapers Survey.

Buckwalter, W., \& Stich, S. (2010). Gender and Philosophical Intuition. In J. Knobe \& S. Nichols (Eds.), Experimental Philosophy (Vol. 2, pp. 307-346). Oxford University Press. https://papers.ssrn.com/sol3/papers.cfm?abstract_id=1966324

Byrd, N. (2014). Intuitive and Reflective Responses in Philosophy [Master's Thesis, University of Colorado]. http://philsci-archive.pitt.edu/12653/

Byrd, N. (2020). Reflection For Real People [Doctoral Thesis]. Florida State University.

Byrd, N. (2021). Reflective Reasoning \& Philosophy. Philosophy Compass, 16(11), e12786. https://doi.org/10.1111/phc3.12786

Byrd, N. (2022). All Measures Are Not Created Equal: Reflection test, think aloud, and process dissociation protocols. https://researchgate.net/publication/344207716

Byrd, N., \& Białek, M. (2021). Your Health vs. My Liberty: Philosophical beliefs dominated reflection and identifiable victim effects when predicting public health recommendation compliance. Cognition, 212. https://doi.org/10.1016/j.cognition.2021.104649

Byrd, N., \& Conway, P. (2019). Not all who ponder count costs: Arithmetic reflection predicts utilitarian tendencies, but logical reflection predicts both deontological and utilitarian tendencies. Cognition, 192, 103995. https://doi.org/10.1016/j.cognition.2019.06.007

Byrd, N., Gongora, G., Joseph, B., \& Sirota, M. (2022). Tell Us What You Really Think: A Think Aloud Protocol Analysis of the Verbal Cognitive Reflection Test. https://researchgate.net/publication/341131477

Campitelli, G., \& Labollita, M. (2010). Correlations of cognitive reflection with judgments and choices. Judgment and Decision Making, 5(3), 182-191.

Cappelen, H. (2012). Philosophy without intuitions (1st ed.). Oxford University Press.

Capraro, V., \& Peltola, N. (2018). Lack of deliberation drives honesty among men but not women. ArXiv:1805.08316 [Physics, q-Bio]. http://arxiv.org/abs/1805.08316

Chalmers, D. J. (2014). Intuitions in philosophy: A minimal defense. Philosophical Studies, 171(3), 535-544. https://doi.org/10.1007/s11098-014-0288-x

Climenhaga, N. (2018). Intuitions are Used as Evidence in Philosophy. Mind, 127(505), 69-104. https://doi.org/10.1093/mind/fzw032

Cokely, E. T., Galesic, M., Schulz, E., Ghazal, S., \& Garcia-Retamero, R. (2012). Measuring risk literacy: The Berlin Numeracy Test. Judgment and Decision Making, 7(1), 25. http://search.proquest.com/docview/1011295450/abstract/88072502EA77452DPQ/1 
Conway, P., \& Gawronski, B. (2013). Deontological and utilitarian inclinations in moral decision making: A process dissociation approach. Journal of Personality and Social Psychology, 104(2), 216-235. https://doi.org/10.1037/a0031021

Conway, P., Goldstein-Greenwood, J., Polacek, D., \& Greene, J. D. (2018). Sacrificial utilitarian judgments do reflect concern for the greater good: Clarification via process dissociation and the judgments of philosophers. Cognition, 179, 241-265. https://doi.org/10.1016/j.cognition.2018.04.018

Cullen, S. (2010). Survey-Driven Romanticism. Review of Philosophy and Psychology, 1(2), 275-296. https://doi.org/10.1007/s13164-009-0016-1

Curtin, F., \& Schulz, P. (1998). Multiple correlations and bonferroni's correction. Biological Psychiatry, 44(8), 775777. https://doi.org/10.1016/S0006-3223(98)00043-2

Dames, H., Klauer, K. C., \& Ragni, M. (2021). The stability of syllogistic reasoning performance over time. Thinking \& Reasoning. https://doi.org/10.1080/13546783.2021.1992012

de Bruin, B. (2021). Knowledge attribution, socioeconomic status, and education: New results using the Great British Class Survey. Synthese, 199(3), 7615-7657. https://doi.org/10.1007/s11229-021-03131-6

De Cruz, H. (2014). Where Philosophical Intuitions Come From. Australasian Journal of Philosophy, 0(0), 1-17. https://doi.org/10.1080/00048402.2014.967792

Deppe, K. D., Gonzalez, F. J., Neiman, J. L., Jacobs, C., Pahlke, J., Smith, K. B., \& Hibbing, J. R. (2015). Reflective liberals and intuitive conservatives: A look at the Cognitive Reflection Test and ideology. Judgment and Decision Making, 10(4), 314-331. sas.upenn.edu/ baron/journal/15/15311/jdm15311.html

Doris, J. M. (2015). Talking to Our Selves: Reflection, Ignorance, and Agency. OUP Oxford.

Easton, C. (2018). Women and 'the philosophical personality': Evaluating whether gender differences in the Cognitive Reflection Test have significance for explaining the gender gap in Philosophy. Synthese. https://doi.org/10.1007/s11229-018-01986-w

Enke, B., Gneezy, U., Hall, B., Martin, D. C., Nelidov, V., Offerman, T., \& van de Ven, J. (2021). Cognitive Biases: Mistakes or Missing Stakes? (Working Paper No. 28650; Working Paper Series). National Bureau of Economic Research. https://doi.org/10.3386/w28650

Erceg, N., Galić, Z., \& Bubić, A. (2019). “Dysrationalia” Among University Students: The Role of Cognitive Abilities, Different Aspects of Rational Thought and Self-Control in Explaining Epistemically Suspect Beliefs. Europe's Journal of Psychology, 15(1), 159-175. https://doi.org/10.5964/ejop.v15i1.1696

Erceg, N., Galic, Z., \& Ružojčić, M. (2020). A reflection on cognitive reflection - testing convergent validity of two versions of the Cognitive Reflection Test. Judgment \& Decision Making, 15(5), 741-755. https://doi.org/10.31234/osf.io/ewrtq

Evans, J. S. B. T. (2019). Reflections on reflection: The nature and function of type 2 processes in dual-process theories of reasoning. Thinking \& Reasoning, $0(0), 1-33$. https://doi.org/10.1080/13546783.2019.1623071

Faul, F., Erdfelder, E., Lang, A.-G., \& Buchner, A. (2007). G*Power 3: A flexible statistical power analysis program for the social, behavioral, and biomedical sciences. Behavior Research Methods, 39(2), 175-191. https://doi.org/10.3758/BF03193146

Feltz, A., \& Cokely, E. (2019). Extraversion and compatibilist intuitions: A ten-year retrospective and metaanalyses. Philosophical Psychology, 32(3), 388-403. https://doi.org/10.1080/09515089.2019.1572692

Feltz, A., \& Cokely, E. T. (2008). The Fragmented Folk: More Evidence of Stable Individual Differences in Moral Judgments and Folk Intuitions. In B. C. Love, K. McRae, \& V. M. Sloutsky (Eds.), Proceedings of the 30th Annual Conference of the Cognitive Science Society. (pp. 1771-1776). Cognitive Science Society.

Fischer, E., \& Engelhardt, P. E. (2020). Lingering stereotypes: Salience bias in philosophical argument. Mind \& Language, 35(4), 415-439. https://doi.org/10.1111/mila.12249

Foot, P. (1967). The Problem of Abortion and the Doctrine of Double Effect. Oxford Review, 5, 5-15.

Foot, P. (1995). Moral dilemmas revisited. In W. Sinnott-Armstrong (Ed.), Modality, Morality and Belief: Essays in Honor of Ruth Barcan Marcus (pp. 117-128). Cambridge University Press.

Frederick, S. (2005). Cognitive Reflection and Decision Making. Journal of Economic Perspectives, 19(4), $25-42$. https://doi.org/10.1257/089533005775196732 
Friesdorf, R., Conway, P., \& Gawronski, B. (2015). Gender Differences in Responses to Moral Dilemmas A Process Dissociation Analysis. Personality and Social Psychology Bulletin, 41(5), 696-713. https://doi.org/10.1177/0146167215575731

Gerber, A. S., Huber, G. A., Doherty, D., \& Dowling, C. M. (2011). The Big Five Personality Traits in the Political Arena. Annual Review of Political Science, 14(1), 265-287. https://doi.org/10.1146/annurev-polisci051010-111659

Gervais, W. M., Najle, M., Schiavone, S. R., \& Caluori, N. (in prep.). The Origins of Religious Disbelief: A Dual Inheritance Approach. https://psyarxiv.com/e29rt/

Gervais, W. M., van Elk, M., Xygalatas, D., McKay, R. T., Aveyard, M., Buchtel, E. E., Dar-Nimrod, I., Klocová, E. K., Ramsay, J. E., Riekki, T., Svedholm-Häkkinen, A. M., \& Bulbulia, J. (2018). Analytic atheism: A cross-culturally weak and fickle phenomenon? Judgment and Decision Making, 13(3), 268-274. https://econpapers.repec.org/article/jdmjournl/v_3a13_3ay_3a2018_3ai_3a3_3ap_3a268-274.htm

Gette, C. R., \& Kryjevskaia, M. (2019). Establishing a relationship between student cognitive reflection skills and performance on physics questions that elicit strong intuitive responses. Physical Review Physics Education Research, 15(1), 010118. https://doi.org/10.1103/PhysRevPhysEducRes.15.010118

Gianotti, L. R., Mohr, C., Pizzagalli, D., Lehmann, D., \& Brugger, P. (2001). Associative processing and paranormal belief. Psychiatry and Clinical Neurosciences, 55(6), 595-603.

Gignac, G. E., \& Szodorai, E. T. (2016). Effect size guidelines for individual differences researchers. Personality and Individual Differences, 102, 74-78. https://doi.org/10.1016/j.paid.2016.06.069

Goodman, N. (1983). Fact, Fiction, and Forecast. Harvard University Press.

Gosling, S. D., Rentfrow, P. J., \& Swann Jr., W. B. (2003). A very brief measure of the Big-Five personality domains. Journal of Research in Personality, 37(6), 504-528. https://doi.org/10.1016/S00926566(03)00046-1

Greene, J. D. (2013). Moral Tribes: Emotion, Reason, and the Gap Between Us and Them. Penguin.

Haidt, J., Koller, S. H., \& Dias, M. G. (1993). Affect, culture, and morality, or is it wrong to eat your dog? Journal of Personality and Social Psychology, 65(4), 613-628. https://doi.org/10.1037/0022-3514.65.4.613

Hannikainen, I., \& Cova, F. (In prep.). Trait reflectivity and consequentialist moral principles: Meta-analytic evidence.

Hannikainen, I. R., Machery, E., Rose, D., Stich, S., Olivola, C. Y., Sousa, P., Cova, F., Buchtel, E. E., Alai, M., Angelucci, A., Berniûnas, R., Chatterjee, A., Cheon, H., Cho, I.-R., Cohnitz, D., Dranseika, V., Eraña Lagos, Á., Ghadakpour, L., Grinberg, M., ... Zhu, J. (2019). For Whom Does Determinism Undermine Moral Responsibility? Surveying the Conditions for Free Will Across Cultures. Frontiers in Psychology, 10. https://doi.org/10.3389/fpsyg.2019.02428

Harris, M. A., Brett, C. E., Johnson, W., \& Deary, I. J. (2016). Personality Stability From Age 14 to Age 77 Years. Psychology and Aging, 31(8), 862-874. https://doi.org/10.1037/pag0000133

Henrich, J., Heine, S. J., \& Norenzayan, A. (2010). The weirdest people in the world? Behavioral and Brain Sciences, 33(2-3), 61-83. https://doi.org/10.1017/S0140525X0999152X

Hertzog, C., Smith, R. M., \& Ariel, R. (2018). Does the Cognitive Reflection Test actually capture heuristic versus analytic reasoning styles in older adults? Experimental Aging Research, 44(1), 18-34. https://doi.org/10.1080/0361073X.2017.1398508

Holtzman, G. (2013). Do Personality Effects Mean Philosophy is Intrinsically Subjective? Journal of Consciousness Studies, 20(5-6), 5-6. https://philpapers.org/rec/HOLDPE

Hursthouse, R. (1999). On Virtue Ethics. Oxford University Press.

Johnson-Laird, P., \& Bara, B. G. (1984). Syllogistic inference. Cognition, 16(1), 1-61. https://doi.org/10.1016/00100277(84)90035-0

Kahane, G. (2015). Sidetracked by trolleys: Why sacrificial moral dilemmas tell us little (or nothing) about utilitarian judgment. Social Neuroscience, O(0), 1-10. https://doi.org/10.1080/17470919.2015.1023400 
Kahane, G., Everett, J. A. C., Earp, B. D., Farias, M., \& Savulescu, J. (2015). 'Utilitarian' judgments in sacrificial moral dilemmas do not reflect impartial concern for the greater good. Cognition, 134, 193-209. https://doi.org/10.1016/j.cognition.2014.10.005

Kim, M., \& Yuan, Y. (2015). No Cross-Cultural Differences In The Gettier Car Case Cast Intuition: A Replication Study Of Weinberg et al. 2001. Episteme, 12(3), 355-361. https://doi.org/10.1017/epi.2015.17

Kitayama, S., Karasawa, M., Grossmann, I., Na, J., Varnum, M. E. W., \& Nisbett, R. (2019). East-West Differences in Cognitive Style and Social Orientation: Are They Real? [Preprint]. PsyArXiv. https://doi.org/10.31234/osf.io/c57ep

Klein, R. A., Vianello, M., Hasselman, F., Adams, B. G., Adams, R. B., Alper, S., Aveyard, M., Axt, J. R., Babalola, M. T., Bahník, Š., Batra, R., Berkics, M., Bernstein, M. J., Berry, D. R., Bialobrzeska, O., Binan, E. D., Bocian, K., Brandt, M. J., Busching, R., ... Nosek, B. A. (2018). Many Labs 2: Investigating Variation in Replicability Across Samples and Settings. Advances in Methods and Practices in Psychological Science, 1(4), 443-490. https://doi.org/10.1177/2515245918810225

Kneer, M., Colaço, D., Alexander, J., \& Machery, E. (2022). On second thought: A refutation of the reflection defense. In J. Knobe, T. Lombrozo, \& S. Nichols (Eds.), Oxford Studies of Experimental Philosophy (Vol. 4, pp. 257-296). Oxford University Press.

Knobe, J. (2021). Philosophical Intuitions Are Surprisingly Stable Across both Demographic Groups and Situations. Filozofia Nauki, 29, 1-66. https://doi.org/10.14394/filnau.2021.0007

Knobe, J. (2022). Difference and Robustness in the Patterns of Philosophical Intuition Across Demographic Groups. Review of Philosophy and Psychology. https://philpapers.org/rec/KNODAR

Knutsen, J. A., \& Presser, S. (2010). Question and Questionnaire Design. In Handbook of Survey Research (2nd ed., pp. 263-313). Emerald.

Kornblith, H. (1998). The role of intuition in philosophical inquiry: An account with no unnatural ingredients. In M. Depaul \& W. Ramsey (Eds.), Rethinking Intuition: The Psychology of Intuition and Its Role in Philosophical Inquiry (pp. 129-141). Rowman \& Littlefield.

Korsgaard, C. M. (1996). The Sources of Normativity. Cambridge University Press.

Lee, S., Kawachi, I., Berkman, L. F., \& Grodstein, F. (2003). Education, Other Socioeconomic Indicators, and Cognitive Function. American Journal of Epidemiology, 157(8), 712-720. https://doi.org/10.1093/aje/kwg042

Liberali, J. M., Reyna, V. F., Furlan, S., Stein, L. M., \& Pardo, S. T. (2012). Individual Differences in Numeracy and Cognitive Reflection, with Implications for Biases and Fallacies in Probability Judgment. Journal of Behavioral Decision Making, 25(4), 361-381. https://doi.org/10.1002/bdm.752

Livengood, J., Sytsma, J., Feltz, A., Scheines, R., \& Machery, E. (2010). Philosophical temperament. Philosophical Psychology, 23(3), 313-330. https://doi.org/10.1080/09515089.2010.490941

Machery, E. (2017). Philosophy Within Its Proper Bounds (1 edition). Oxford University Press.

Machery, E. (2021). A Mistaken Confidence in Data. European Journal for Philosophy of Science, 11(2), 1-17. https://doi.org/10.1007/s13194-021-00354-9

Machery, E., Mallon, R., Nichols, S., \& Stich, S. P. (2004). Semantics, cross-cultural style. Cognition, 92(3), B1B12. https://doi.org/10.1016/j.cognition.2003.10.003

Mækelæ, M. J., Moritz, S., \& Pfuhl, G. (2018). Are Psychotic Experiences Related to Poorer Reflective Reasoning? Frontiers in Psychology, 9. https://doi.org/10.3389/fpsyg.2018.00122

Mallon, R. (2016). Intuitive Diversity and Disagreement. In J. Nado (Ed.), Advances in Experimental Philosophy and Philosophical Methodology (pp. 99-123). Bloomsbury Press.

Mandelbaum, E., \& Ripley, D. (2012). Explaining the Abstract/Concrete Paradoxes in Moral Psychology: The NBAR Hypothesis. Review of Philosophy and Psychology, 3(3), 351-368. https://doi.org/10.1007/s13164012-0106-3

Markovits, H., \& Nantel, G. (1989). The belief-bias effect in the production and evaluation of logical conclusions. Memory \& Cognition, 17(1), 11-17. https://doi.org/10.3758/BF03199552 
Martiny-Huenger, T., Bieleke, M., Doerflinger, J., Stephensen, M. B., \& Gollwitzer, P. M. (2020). Deliberation decreases the likelihood of expressing dominant responses. Psychonomic Bulletin \& Review. https://doi.org/10.3758/s13423-020-01795-8

Meyer, A., Frederick, S., Burnham, T. C., Guevara Pinto, J. D., Boyer, T. W., Ball, L. J., Pennycook, G., Ackerman, R., Thompson, V. A., \& Schuldt, J. P. (2015). Disfluent fonts don't help people solve math problems. Journal of Experimental Psychology: General, 144(2), e16-e30. https://doi.org/10.1037/xge0000049

Nahmias, E., Coates, D. J., \& Kvaran, T. (2007). Free will, moral responsibility, and mechanism: Experiments on folk intuitions. Midwest Studies in Philosophy, 31(1), 214-242. https://doi.org/10.1111/j.14754975.2007.00158.x

Patel, N. (2017). The Cognitive Reflection Test: A measure of intuition/reflection, numeracy, and insight problem solving, and the implications for understanding real-world judgments and beliefs [Thesis, University of Missouri--Columbia]. https://mospace.umsystem.edu/xmlui/handle/10355/62365

Patil, I., Zucchelli, M. M., Kool, W., Campbell, S., Fornasier, F., Calò, M., Silani, G., Cikara, M., \& Cushman, F. (2021). Reasoning supports utilitarian resolutions to moral dilemmas across diverse measures. Journal of Personality and Social Psychology, 120(2), 443-460. https://doi.org/10.1037/pspp0000281

Pelc, J. (1969). Nominal Expressions and their Real or Fictitious Referents. Akten Des XIV. Internationalen Kongresses Für Philosophie, 3, 484-485. https://doi.org/10.5840/wcp141969396

Pennycook, G., Cheyne, J. A., Barr, N., Koehler, D. J., \& Fugelsang, J. A. (2014). Cognitive style and religiosity: The role of conflict detection. Memory \& Cognition, 42(1), 1-10. https://doi.org/10.3758/s13421-0130340-7

Pennycook, G., Cheyne, J. A., Koehler, D. J., \& Fugelsang, J. A. (2013). Belief bias during reasoning among religious believers and skeptics. Psychonomic Bulletin \& Review, 20(4), 806-811. https://doi.org/10.3758/s13423-013-0394-3

Pennycook, G., Cheyne, J. A., Seli, P., Koehler, D. J., \& Fugelsang, J. A. (2012). Analytic cognitive style predicts religious and paranormal belief. Cognition, 123(3), 335-346. https://doi.org/10.1016/j.cognition.2012.03.003

Pennycook, G., Ross, R. M., Koehler, D. J., \& Fugelsang, J. A. (2016). Atheists and Agnostics Are More Reflective than Religious Believers: Four Empirical Studies and a Meta-Analysis. PLOS ONE, 11(4), e0153039. https://doi.org/10.1371/journal.pone.0153039

Pinillos, N. Á., Smith, N., Nair, G. S., Marchetto, P., \& Mun, C. (2011). Philosophy's new challenge: Experiments and intentional action. Mind \& Language, 26(1), 115-139.

Price-Blackshear, M. A., Sheldon, K. M., Corcoran, M. J., \& Bettencourt, B. A. (2019). Individuating information influences partisan judgments. Journal of Applied Social Psychology. https://doi.org/10.1111/jasp.12595

Primi, C., Donati, M. A., Chiesi, F., \& Morsanyi, K. (2018). Are there gender differences in cognitive reflection? Invariance and differences related to mathematics. Thinking \& Reasoning, 24(2), 258-279. https://doi.org/10.1080/13546783.2017.1387606

Primi, C., Morsanyi, K., Chiesi, F., Donati, M. A., \& Hamilton, J. (2016). The Development and Testing of a New Version of the Cognitive Reflection Test Applying Item Response Theory (IRT). Journal of Behavioral Decision Making, 29(5), 453-469. https://doi.org/10.1002/bdm.1883

Rawls, J. (1971). A Theory of Justice (Revised edition). Belknap Press.

Reynolds, C. J., Byrd, N., \& Conway, P. (2022). Trait reflectiveness and responses to moral dilemmas: A metaanalytic process dissociation approach. https://osf.io/kj7cv

Reynolds, C. J., Makhanova, A., Ng, B. K. L., \& Conway, P. (2019). Bound together for God and country: The binding moral foundations link unreflectiveness with religiosity and political conservatism. Personality and Individual Differences, 109632. https://doi.org/10.1016/j.paid.2019.109632

Robbins, E., Shepard, J., \& Rochat, P. (2017). Variations in judgments of intentional action and moral evaluation across eight cultures. Cognition, 164, 22-30. https://doi.org/10.1016/j.cognition.2017.02.012

Rohrer, J. M., Hünermund, P., Arslan, R. C., \& Elson, M. (2021). That's a lot to PROCESS! Pitfalls of Popular Path Models. https://doi.org/10.31234/osf.io/paeb7 
Saroglou, V. (2002). Religion and the five factors of personality: A meta-analytic review. Personality and Individual Differences, 32(1), 15-25. https://doi.org/10.1016/S0191-8869(00)00233-6

Schoemann, A. M., Boulton, A. J., \& Short, S. D. (2017). Determining Power and Sample Size for Simple and Complex Mediation Models. Social Psychological and Personality Science, 8(4), 379-386. https://doi.org/10.1177/1948550617715068

Seyedsayamdost, H. (2015). On Normativity and Epistemic Intuitions: Failure of Replication. Episteme, 12(1), 95116. https://doi.org/10.1017/epi.2014.27

Sidgwick, H. (1874). The Methods Of Ethics (7th ed.). Hackett Publishing.

Sinnott-Armstrong, W. (2007). Abstract + Concrete = Paradox. In J. Knobe \& S. Nichols (Eds.), Experimental Philosophy. Oxford University Press.

Sirota, M., \& Juanchich, M. (2018). Effect of response format on cognitive reflection: Validating a two- and fouroption multiple choice question version of the Cognitive Reflection Test. Behavior Research Methods, 50(6), 2511-2522. https://doi.org/10.3758/s13428-018-1029-4

Sirota, M., Kostovičová, L., Juanchich, M., Dewberry, C., \& Marshall, A. C. (2020). Measuring Cognitive Reflection without Maths: Developing and Validating the Verbal Cognitive Reflection Test. Journal of Behavioral Decision Making. https://doi.org/10.1002/bdm.2213

Sosa, E. (1991). Knowledge in Perspective: Selected Essays in Epistemology. Cambridge University Press.

Stagnaro, M. N., Pennycook, G., \& Rand, D. G. (2018). Performance on the Cognitive Reflection Test is stable across time. Judgment and Decision Making, 13(3), 260-267. https://ideas.repec.org/a/jdm/journl/v13y2018i3p260-267.html

Stagnaro, M., Pennycook, G., \& Rand, D. G. (2018). Cognitive Reflection is a Stable Trait (SSRN Scholarly Paper ID 3115809). Social Science Research Network. https://papers.ssrn.com/abstract=3115809

Stich, S. P., \& Machery, E. (2022). Demographic Differences in Philosophical Intuition: A Reply to Joshua Knobe. Review of Philosophy and Psychology. https://doi.org/10.1007/s13164-021-00609-7

Stieger, S., \& Reips, U.-D. (2016). A limitation of the Cognitive Reflection Test: Familiarity. PeerJ, 4, e2395. https://doi.org/10.7717/peerj.2395

Strimaitis, J. (2018). Conditional reflection and the Religion Reflection Scale: How familiarity with different domains influences cognitive reflection [Master's Thesis, University of Tennessee at Chattanooga]. https://scholar.utc.edu/theses/556

Szaszi, B., Szollosi, A., Palfi, B., \& Aczel, B. (2017). The cognitive reflection test revisited: Exploring the ways individuals solve the test. Thinking \& Reasoning, 23(3), 207-234. https://doi.org/10.1080/13546783.2017.1292954

Taylor, C. (1976). Responsibility for Self. In A. O. Rorty (Ed.), The Identities of Persons (pp. 281-299). University of California Press.

Thompson, V. A., Turner, J. A. P., Pennycook, G., Ball, L. J., Brack, H., Ophir, Y., \& Ackerman, R. (2013). The role of answer fluency and perceptual fluency as metacognitive cues for initiating analytic thinking. Cognition, 128(2), 237-251. https://doi.org/10.1016/j.cognition.2012.09.012

Tobia, K., Buckwalter, W., \& Stich, S. (2013). Moral intuitions: Are philosophers experts? Philosophical Psychology, 26(5), 629-638. https://doi.org/10.1080/09515089.2012.696327

van Dongen, N., Colombo, M., Romero, F., \& Sprenger, J. (2019). Intuitions about the Reference of Proper Names: A Meta-Analysis. https://doi.org/10.31234/osf.io/ez96q

Weinberg, J. M., Nichols, S., \& Stich, S. (2001). Normativity and epistemic intuitions. Philosophical Topics, 29(12), 429-460. https://doi.org/10.5840/philtopics2001291/217

Weiss, A., Dorrough, A. R., \& Schmitz, L. (2021). Analytic atheism in a low-religiosity culture: Examining the relationship between analytic thinking and religious belief in Germany. Personality and Individual Differences, 178, 110854. https://doi.org/10.1016/j.paid.2021.110854

Welsh, M. B., \& Begg, S. H. (2017, July). The Cognitive Reflection Test: Familiarity and predictive power in professionals. Annual Meeting of the Cognitive Science Society, London. https://mindmodeling.org/cogsci2017/papers/0659/paper0659.pdf 
White, C. J. M., Willard, A. K., Baimel, A., \& Norenzayan, A. (2021). Cognitive Pathways to Belief in Karma and Belief in God. Cognitive Science, 45(1), e12935. https://doi.org/10.1111/cogs.12935

Wilkenfeld, D. A. (2020). Moral understanding and moral illusions. Thought: A Journal of Philosophy, 9(1), 25-33. https://doi.org/10.1002/tht3.438

Williamson, T. (2007). The philosophy of philosophy. Blackwell Pub.

Winskel, H., \& Bhatt, D. (2019). The role of culture and language in moral decision-making. Culture and Brain. https://doi.org/10.1007/s40167-019-00085-y

Yaden, D. B., \& Anderson, D. E. (2021). The psychology of philosophy: Associating philosophical views with psychological traits in professional philosophers. Philosophical Psychology. https://doi.org/10.1080/09515089.2021.1915972

Yilmaz, O., \& Alper, S. (2019). The link between intuitive thinking and social conservatism is stronger in WEIRD societies. Judgment and Decision Making, 14(2). http://journal.sjdm.org/18/181212/jdm181212.html

Yilmaz, O., \& Isler, O. (2019). Reflection increases belief in God through self-questioning among non-believers. Judgment and Decision Making, 14(6), 649-657. http://journal.sjdm.org/19/190605/jdm190605.html

Yilmaz, O., Saribay, A. S., \& Iyer, R. (2019). Are neo-liberals more intuitive? Undetected libertarians confound the relation between analytic cognitive style and economic conservatism. Current Psychology. https://doi.org/10.1007/s12144-019-0130-x

Yılmaz, O., \& Sarıbay, S. A. (2016). An attempt to clarify the link between cognitive style and political ideology: A non-western replication and extension. Judgment and Decision Making, 11(3), 287-300. http://journal.sjdm.org/vol11.3.html

Zuckerman, M., Li, C., Lin, S., \& Hall, J. A. (2019). The Negative Intelligence-Religiosity Relation: New and Confirming Evidence. Personality and Social Psychology Bulletin, 0146167219879122. https://doi.org/10.1177/0146167219879122 


\section{Prior Study}

Participants. The prior study used LeiterReports.typepad.com to recruit 979 respondents starting in 2014. An a priori decision was made to exclude all incomplete surveys $(n=382)$ and patently insincere surveys $(n=3)$ i.e., one participant reported that their ethnicity was "Handsome" and two participants reported that they were citizens of the countries "Texas" and "Narnia". The final sample of 594 (106 identified as women, 483 as men, and 5 as other; 485 identified as White, 37 as Multiethnic, 23 as Asian, 22 as Hispanic or Latino, 4 as Black, 3 as Caribbean, 1 as American Indian or Native American, and 19 as other ethnicity).

Procedure and materials. Data for this prior study were collected in 2014 using Qualtrics in accordance with University of Colorado IRB protocol \#13-0678 (Byrd, 2014)—see the Open Science link in the main text. Participants in this study completed measures of philosophical beliefs, reflection, class, and culture.

All items from the replication. Details about most of the measures in this study can be found in main text about the replication, unless otherwise stated in the main text or below.

Culture. All participants in the prior study were asked to report their country of citizenship. Table A1 shows how these responses were sorted as WEIRD or non-WEIRD countries based on earlier work (Klein et al., 2018; Yilmaz \& Alper, 2019). This study barely recruited enough participants from non-WEIRD nations to detect smaller effects of country-based cultural differences. Without a reason to expect the replication to overcome this limitation, the citizenship question was not included in the replication.

Results. Many correlations from the prior study were smaller than anticipated. In fact, its correlations were as small as $r=0.08$. Posthoc power analysis suggests that the prior had $62 \%$ power to detect such a small correlation (Faul, Erdfelder, Lang, \& Buchner, 2007). A sample size of 964 participants would have been required for $80 \%$ power to detect such small correlations (ibid.). This is one of the reasons that a larger replication was pre-registered and deployed. 
Table A1. List of countries and their sample sizes from prior study.

\begin{tabular}{llll}
\multicolumn{1}{c}{ Non-WEIRD Nations } & \multicolumn{2}{c}{ WEIRD Nations } \\
\hline Country & N & Country & N \\
\hline Brazil & 10 & Australia & 12 \\
China & 2 & Canada & 47 \\
Costa Rica & 2 & Chile & 1 \\
Dominican Republic & 1 & Denmark & 1 \\
Ecuador & 2 & Finland & 1 \\
Hong Kong (China) & 2 & France & 4 \\
India & 6 & Germany & 9 \\
Lithuania & 1 & Hungary & 1 \\
Malaysia & 1 & Iceland & 1 \\
Mexico & 2 & Israel & 1 \\
Nepal & 1 & Italy & 5 \\
Peru & 1 & New Zealand & 6 \\
Romania & 2 & Norway & 2 \\
Russia & 1 & South Korea & 2 \\
Singapore & 1 & Spain & 1 \\
Taiwan (China) & 1 & Sweden & 7 \\
Turkey & 1 & Switzerland & 2 \\
& & The Netherlands & 4 \\
& & United Kingdom & 58 \\
& & Unites States & 398 \\
\hline & & &
\end{tabular}



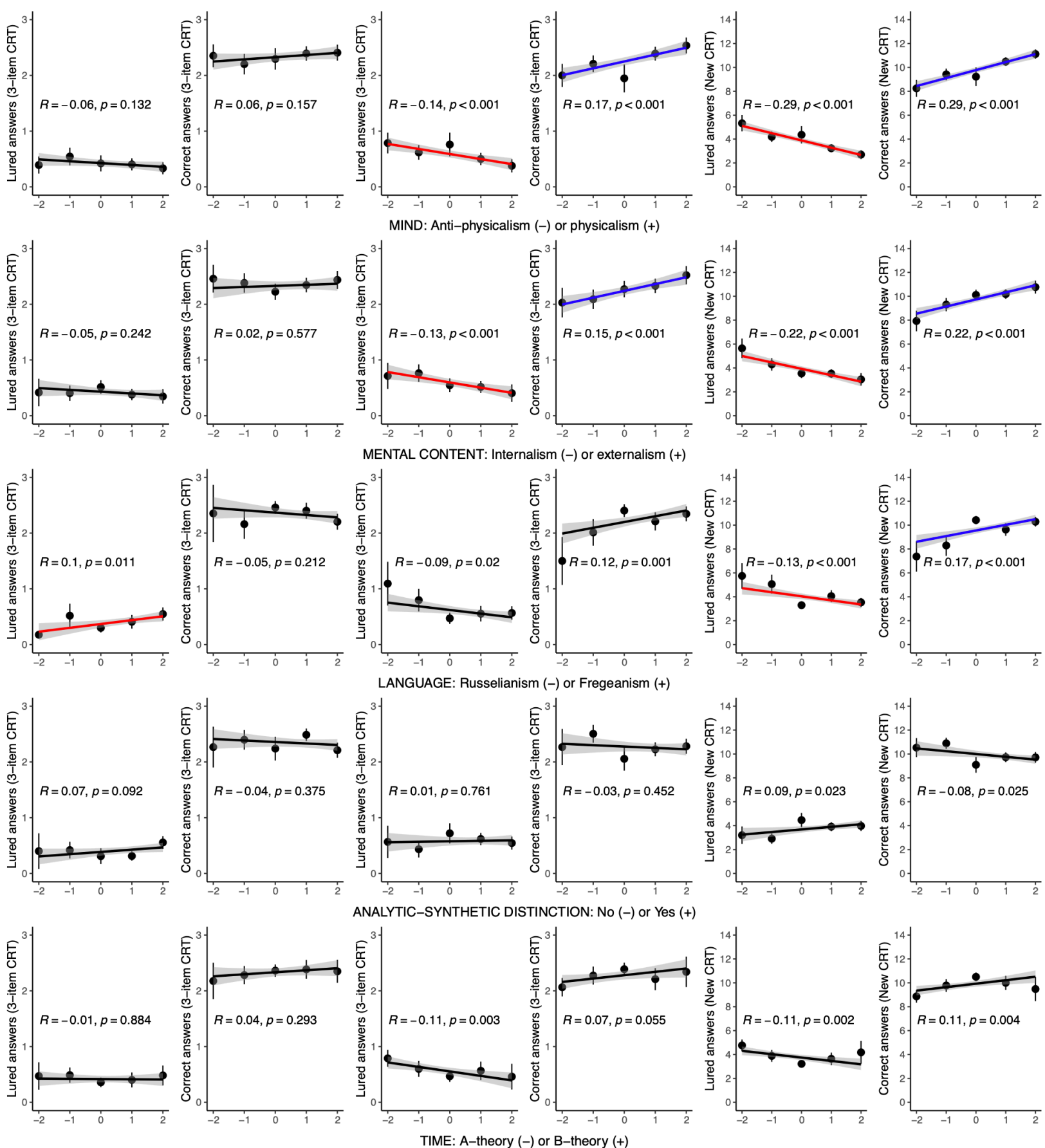

Figure A1. Bivariate reflection-philosophy correlations from the prior study (3-item CRT in two left-most columns, $\mathrm{N}=594$ ) and the replication (3-item CRT in middle two columns and New CRT in right two columns, $\mathrm{N}=705$, right) with $95 \%$ confidence interval bands (grey). Red or blue lines indicates p-values less than 0.05 (prior study) or less than the Bonferroni corrected value of 0.001 (replication). All squared and cubic relations' $95 \%$ confidence intervals almost fully overlapped with these linear relationships. 

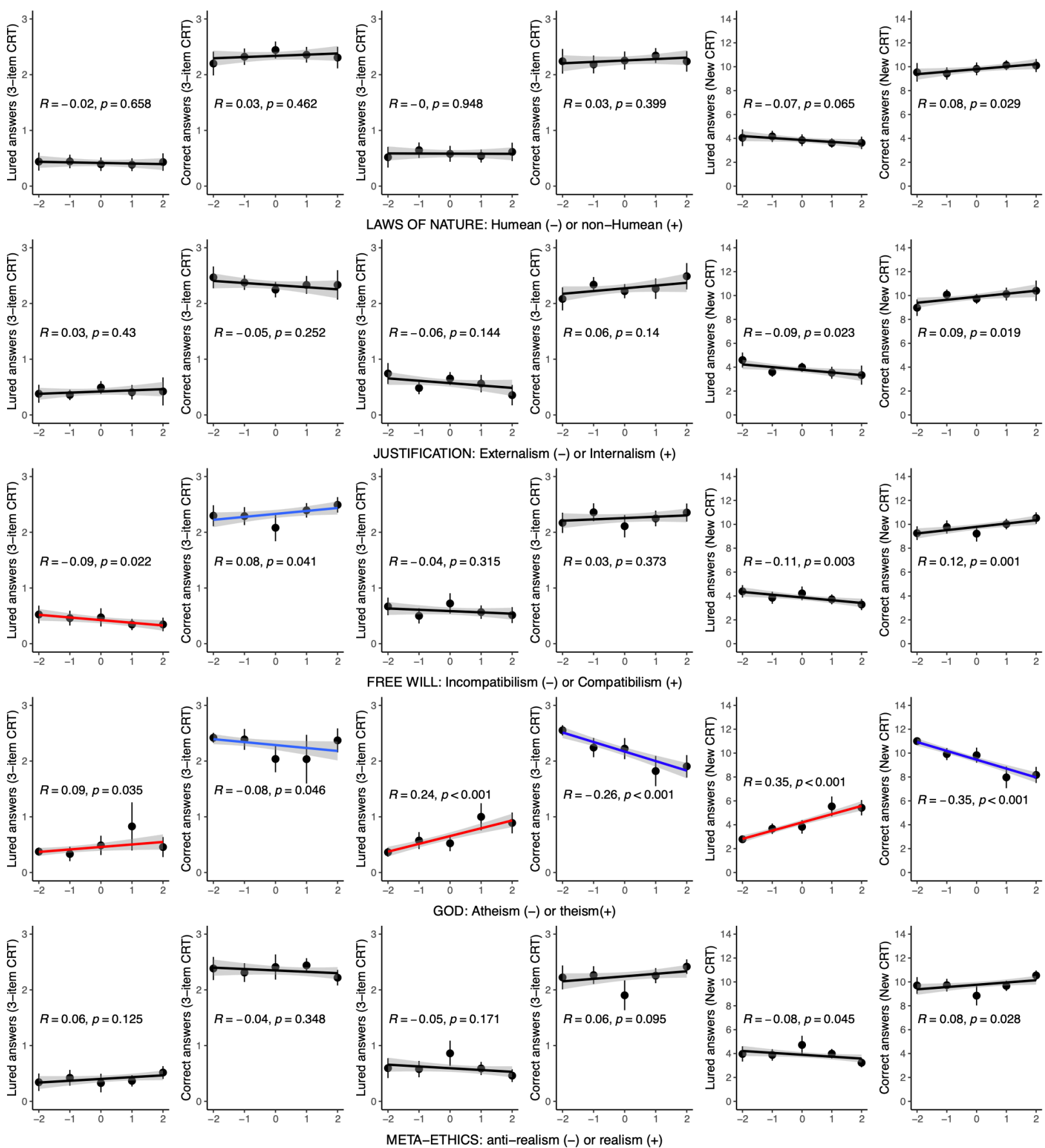

Figure A2. Continued bivariate reflection-philosophy correlations from the prior study (3-item CRT in two left-most columns, $N=594$ ) and the replication (3-item CRT in middle two columns and New CRT in right two columns, $N=$ 705 , right) with 95\% confidence interval bands (grey). Red or blue lines indicates $p$-values less than 0.05 (prior study) or less than the Bonferroni corrected value of 0.001 (replication). All squared and cubic relations' 95\% confidence intervals almost fully overlapped with these linear relationships. 

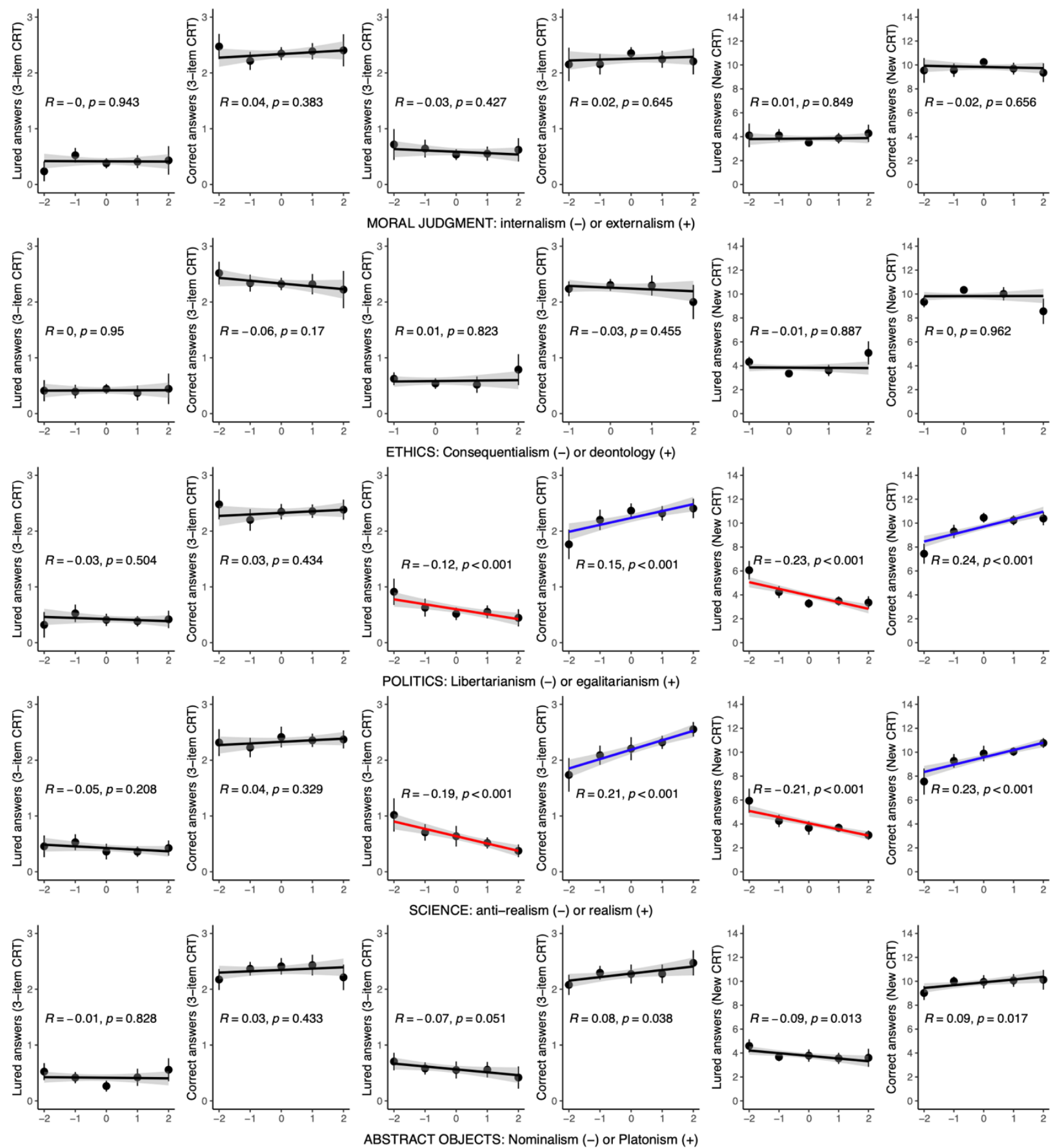

Figure A3. Continued bivariate reflection-philosophy correlations from the prior study (3-item CRT in two left-most columns, $N=594$ ) and the replication (3-item CRT in middle two columns and New CRT in right two columns, $N=$ 705 , right) with $95 \%$ confidence interval bands (grey). Red or blue lines indicates $p$-values less than 0.05 (prior study) or less than the Bonferroni corrected value of 0.001 (replication). All squared and cubic relations' $95 \%$ confidence intervals almost fully overlapped with these linear relationships. 

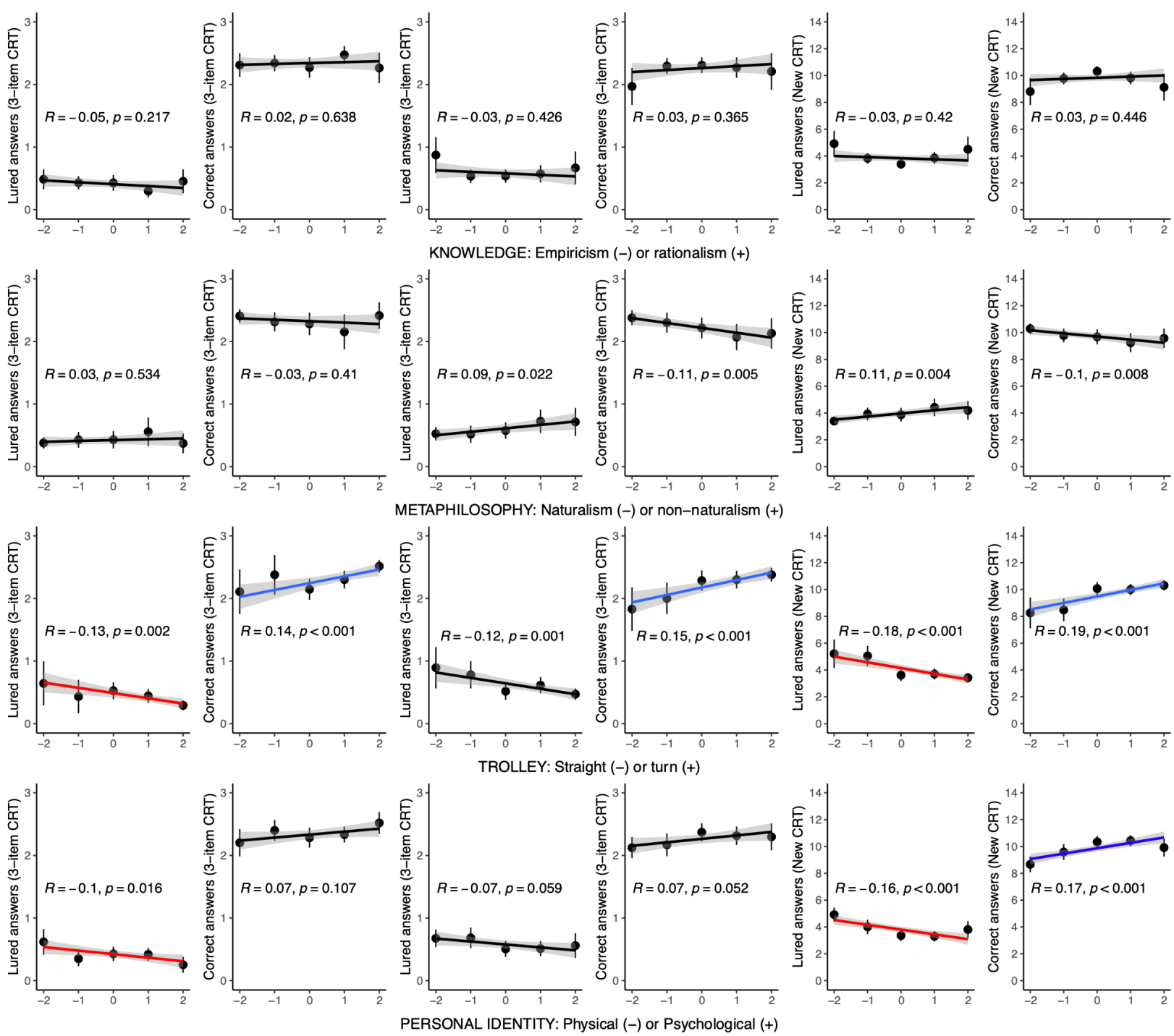

Figure A4. Remaining bivariate reflection-philosophy correlations from the prior study (3-item CRT in two leftmost columns, $N=594$ ) and the replication (3-item CRT in middle two columns and New CRT in right two columns, $N=705$, right) with $95 \%$ confidence interval bands (grey). Red or blue lines indicates $p$-values less than 0.05 (prior study) or less than the Bonferroni corrected value of 0.001 (replication). All squared and cubic relations' $95 \%$ confidence intervals almost fully overlapped with these linear relationships. 
Table A2. Standardized multiple regression coefficients predicting philosophical tendencies (-2 to 2 a la Bourget \& Chalmers, 2014) from all measures in the prior study $(N=594)$. Each column is a separate multiple regression analysis.

\begin{tabular}{|c|c|c|c|c|c|}
\hline & $\begin{array}{l}\text { Language } \\
\text { Russelianism or } \\
\text { Fregenaism? }\end{array}$ & $\begin{array}{c}\text { Free Will } \\
\text { Incompatibilism or } \\
\text { compatibilism? }\end{array}$ & $\begin{array}{l}\text { God } \\
\text { Atheism or } \\
\text { theism? }\end{array}$ & $\begin{array}{l}\text { Trolley Problem } \\
\text { Straight or } \\
\text { turn? }\end{array}$ & $\begin{array}{c}\text { Personal Identity } \\
\text { Physical or } \\
\text { psychological? }\end{array}$ \\
\hline Lured 3-item CRT & $.14^{* *}$ & -.06 & .05 & -.04 & $-.12 \dagger$ \\
\hline Correct 3-item CRT & $.15^{\star *}$ & .01 & -.03 & .06 & -.06 \\
\hline Familiarity with CRT & $-.11^{* *}$ & $.11^{* *}$ & .02 & .03 & -.01 \\
\hline Philosophy Ph.D. & $-.55^{\star * *}$ & $.17^{* * *}$ & -.04 & $.11^{* *}$ & $.28^{* * *}$ \\
\hline Gender $(M-W)$ & .03 & .02 & .00 & $-.16^{* * *}$ & .06 \\
\hline WEIRD nation & $-.06 \dagger$ & $.11^{* *}$ & -.04 & $.07^{\dagger}$ & .02 \\
\hline Extraversion & -.04 & -.03 & .01 & $.09^{*}$ & -.01 \\
\hline Agreeableness & .05 & .05 & $.11^{*}$ & -.03 & .06 \\
\hline Conscientiousness & .00 & -.00 & .02 & $-.09^{*}$ & -.02 \\
\hline Stability & .03 & .05 & -.03 & .05 & -.00 \\
\hline Openness & .03 & $.11^{* *}$ & $-.10^{*}$ & $.09^{*}$ & -.01 \\
\hline Combined Adjusted $R^{2}$ & $.33^{* * *}$ & $.07^{* * *}$ & $.01^{\dagger}$ & $.08^{\star * *}$ & $.09 * * *$ \\
\hline
\end{tabular}

Note: $\uparrow p<.1,{ }^{*} p<.05,{ }^{* *} p<.01,{ }^{* * *} p<.001$ 


\section{PhilPapers Survey Items \& Jargon-free Translations}

Mind: anti-physicalism or physicalism?

- Accept: anti-physicalism

- Lean toward: anti-physicalism

- No inclination

- I don't know

- Lean toward: physicalism

- Accept: physicalism

Mental content: externalism or internalism?

- Accept: externalism

- Lean toward: externalism

- No inclination

- I don't know

- Lean toward: internalism

- Accept: internalism

Language: Russellianism or Fregeanism?

- Accept: Russellianism

- Lean toward: Russellianism

- No inclination

- I don't know

- Lean toward: Fregeanism

- Accept: Fregeanism

Analytic-synthetic distinction: yes or no?

- Accept: yes

- Lean toward: yes

- No inclination

- I don't know

- Lean toward: no

- Accept: no
Do you think the mind is entirely physical or not?

- Accept: it's entirely physical

- Lean toward: it's entirely physical

- No inclination

- I don't know

- Lean toward: it's not entirely physical

- Accept: it's not entirely physical

Do you think the contents of the mind are entirely internal or do the contents of the mind depend on things outside the mind?

- Accept: depends on contents of the world

- Lean toward: depends ... of the world

- No inclination

- I don't know

- Lean toward: entirely internal

- Accept: entirely internal

Do you think that uttering the words like 'Santa Claus' [or 'dolphin'] implies[y] that Santa Claus [or dolphins] actually exists or does it merely imply that an idea of Santa Claus [or dolphin] exists?

- Accept: ... actually exists

- Lean toward: ... actually exists

- No inclination

- I don't know

- Lean toward: ...just an idea ... exists

- Accept: ...just an idea ... exists

Note: Study 1 vs. [Study 2]

Do you think there is an important difference between statements that are true depending on how they describe the world and statements that are true by definition?

- Accept: yes

- Lean toward: yes

- No inclination

- I don't know

- Lean toward: no

- Accept: no 
Time: B-theory or A-theory?

- Accept: B-theory

- Lean toward: B-theory

- No inclination

- I don't know

- Lean toward: A-theory

- Accept: A-theory

Laws of nature: Humeanism or nonHumeanism?

- Accept: Humeanism

- Lean toward: Humeanism

- No inclination

- I don't know

- Lean toward: non-Humeanism

- Accept: non-Humeanism

Justification: externalism or internalism?

- Accept: externalism

- Lean toward: externalism

- No inclination

- I don't know

- Lean toward: internalism

- Accept: internalism

Free will: incompatibilism or compatibilism?

- Accept: incompatibilism

- Lean toward: incompatibilism

- No inclination

- I don't know

- Lean toward: compatibilism

- Accept: compatibilism

God: theism or atheism?

- Accept: theism

- Lean toward: theism

- No inclination

- I don't know

- Lean toward: atheism

- Accept: atheism
Do you think that our experience of time's passage represents an objective passage of time in the world, or do you think that our experience of time's passage is illusory?

- Accept: ... objective passage of time

- Lean toward: ... objective passage of time

- No inclination

- I don't know

- Lean toward: it's illusory

- Accept: it's illusory

Do you think natural laws are just descriptions of observed regularities or are they law-like features that truly govern events such in such a way that observable regularities occur?

- Accept: just descriptions

- Lean toward: just descriptions

- No inclination

- I don't know

- Lean toward: law-like features

- Accept: law-like features

Do you think someone's beliefs and actions should be justified by factors that are "external" (e.g., objective truth or consequences) or "internal" to the person (e.g., motivation, intention, awareness)?

- Accept: external

- Lean toward: external

- No inclination

- I don't know

- Lean toward: internal

- Accept: internal

If every event in the universe is determined, do you think it is possible that there could be free will?

- Accept: no

- Lean toward: no

- No inclination

- I don't know

- Lean toward: yes

- Accept: yes

Do you think that a God exists?

- Accept: yes

- Lean toward: yes

- No inclination

- I don't know

- Lean toward: no

- Accept: no 
Meta-ethics: moral realism or moral antirealism?

- Accept: moral realism

- Lean toward: moral realism

- No inclination

- I don't know

- Accept: moral anti-realism

- Lean toward: moral anti-realism

Moral judgment: externalism or internalism?

- Accept: externalism

- Lean toward: externalism

- No inclination

- I don't know

- Accept: internalism

- Lean toward: internalism

Normative ethics: consequentialism, deontology or virtue ethics?

- Accept: consequentialism

- Lean toward: consequentialism

- Accept: deontology

- Lean toward: deontology

- Accept: virtue ethics

- Lean toward: virtue ethics

- No inclination

- I don't know

Politics: libertarianism or egalitarianism?

- Accept: libertarianism

- Lean toward: libertarianism

- No inclination

- I don't know

- Lean toward: egalitarianism

- Accept: egalitarianism
Is anything objectively or truly morally right or wrong?

- Accept: yes

- Lean toward: yes

- No inclination

- I don't know

- Accept: no

- Lean toward: no

Do you think that moral judgments are justified only by external criteria (e.g., whether or not someone is known to be a good person), or by only factors internal to the person (e.g., whether or not the person was motivated by good intentions)?

- Accept: external

- Lean toward: external

- No inclination

- I don't know

- Accept: internal

- Lean toward: internal

Which of the following do you think makes an action right or wrong?

(a) The consequences of the action.

(b) The definition or intention of the action.

(c) Whether or not the person who did the action was a good person.

- Accept: (a)

- Lean toward: (a)

- Accept: (b)

- Lean toward: (b)

- Accept: virtue (c)

- Lean toward: (c)

- No inclination

- I don't know

What is more important in a good society: ensuring liberty or ensuring equality?

- Accept: liberty

- Lean toward: liberty

- No inclination

- I don't know

- Lean toward: equality

- Accept: equality 
Science: scientific anti-realism or scientific realism?

- Accept: scientific anti-realism

- Lean toward: scientific anti-realism

- No inclination

- I don't know

- Lean toward: scientific realism

- Accept: scientific realism

Abstract objects: nominalism or Platonism?

- Accept: nominalism

- Lean toward: nominalism

- No inclination

- I don't know

- Lean toward: Platonism

- Accept: Platonism

Knowledge: empiricism or rationalism?

- Accept: empiricism

- Lean toward: empiricism

- No inclination

- I don't know

- Accept: rationalism

- Lean toward: rationalism

Metaphilosophy: naturalism or non-naturalism?

- Accept: naturalism

- Lean toward: naturalism

- No inclination

- I don't know

- Lean toward: non-naturalism

- Accept: non-naturalism

Trolley problem (five straight ahead, one on side track, turn requires switching): straight or turn?

- Accept: straight

- Lean toward: straight

- No inclination

- I don't know

- Lean toward: turn

- Accept: turn
Do you think that science can describe the fundamental nature of the world, or can it only produce useful predictions and technology?

- Accept: ...useful predictions and technology

- Lean toward: ...useful predictions and technology

- No inclination

- I don't know

- Lean toward: ... fundamental nature ...

- Accept: ... fundamental nature ...

Do you think abstract entities like numbers really exist, or do things like numbers only exist as descriptions of quantities (for example 3 apples)?

- Accept: only as descriptions

- Lean toward: only as descriptions

- No inclination

- I don't know

- Lean toward: entities that really exist

- Accept: entities that really exist

Do you think we have to see how the world works to have knowledge or can we know things by just thinking about them?

- Accept: we have to see how the world...

- Lean toward: we have to see ...

- No inclination

- I don't know

- Lean toward: we can just think ...

- Accept: we can just think ...

Do you think that there are supernatural forces, causes, or beings?

- Accept: no

- Lean toward: no

- No inclination

- I don't know

- Lean toward: yes

- Accept: yes

You see a train racing down its track towards five people. You happen to be standing near the switch that would divert the train down a sidetrack toward one person. If you pull the switch the train will surely kill 1 person. If you do not pull the switch the train will surely kill five persons. Do you pull the switch?

- Accept: no

- Lean toward: no

- No inclination

- I don't know

- Lean toward: yes

- Accept: yes 
Personal identity: physical view or psychological view?

- Accept: physical view

- Lean toward: physical view

- No inclination

- I don't know

- Lean toward: psychological view

- Accept: psychological view
Do you think that your brain and body have to continue to exist for you to continue to exist, or could you continue to exist so long as your mental states continue to exist?

- Accept: brain and body must continue...

- Lean toward: brain and body ...

- No inclination

- I don't know

- Lean toward: only mental states ...

- Accept: only mental states must cont... 